\title{
HER2-Specific Vaccines for HER2-Positive Breast Cancer Immunotherapy
}

\author{
Maxwell Omabe', Shahid Ahmed², Amer Sami2, Yufeng Xie³, Min Tao3, Jim Xiang1,2* \\ ${ }^{1}$ Cancer Research Cluster, Saskatchewan Cancer Agency, Saskatoon, Canada \\ ${ }^{2}$ Department of Oncology, University of Saskatchewan, Saskatoon, Canada \\ ${ }^{3}$ Department of Oncology, The first Affiliated Hospital, Soo-Chow University, Suzhou, China \\ Email: “iim.xiang@usask.ca
}

Received 19 March 2015; accepted 18 April 2015; published 24 April 2015

Copyright (C) 2015 by author and Scientific Research Publishing Inc.

This work is licensed under the Creative Commons Attribution International License (CC BY). http://creativecommons.org/licenses/by/4.0/

(c) (i) 0pen Access

\section{Abstract}

Anti-human epidermal growth factor receptor-2 (HER2) immunization can be elicited by vaccination with DNA encoding the extra- or intra-cellular domain (ECD or ICD) of HER2, naked or encapsulated in viral vectors. HER2-peptides derived from ECD or ICD of HER2, and HER2-pulsed dendritic cells (DCs) or engineered DCs expressing HER2, respectively. We performed a computerbased literature search which includes but is not limited to the following keywords: breast cancer, immunotherapy, HER2-peptide vaccine, HER2-DNA vaccine, HER-DC vaccine, HER2 vaccine, and HER2/neu, in PubMed, Medline, EMBO and Google Scholar; data from recently reported clinical trials were also included. Drawing upon this synthesis of literature, this work summarizes the development and current trend in experimental and clinical investigations in HER2-positive breast cancer using HER2-specific vaccine and immunotherapy, focusing especially on: (i) DNA-; (ii) peptide-; and (iii) DC-based vaccines. It addresses interventions that have been applied to overcome immunotolerance thereby to improve treatment outcomes. These include blocking the inhibitory cytotoxic T lymphocyte-associated protein-4 (CTLA-4), which is expressed at high levels by regulatory $\mathrm{T}$ (Treg) cells, or complete Treg depletion to improve T-cell activation. Moreover, modulatory interventions can provide further improvement in the efficacy of HER2-specific vaccine. The interventions include the use of immunogenic adjuvants such as cytokines interleukin-12 (IL-12), tumor necrosis factor (TNF)- $\alpha$ and granulocyte-macrophage colony-stimulating factor (GM-CSF), the use of Toll-like receptor (TLR) ligands and tetanus toxin's universal epitopes such as the CD4+ help T (Th)-epitope P30, and the use of either chimeric or heterogenous xenogeneic HER2. Combining active HER2-vaccination with adoptive trastuzumab antibody immunotherapy is likely to increase the effectiveness of each approach alone. The development of effective HER2-vaccines for breast cancer remains a critical challenge. Though these novel interventions seem promising, further investigation is still needed since the results are preliminary. Furthermore, the review discusses the challenges and future perspectives in HER2-vaccine research and development.

\footnotetext{
*Corresponding author.
}

How to cite this paper: Omabe, M., Ahmed, S., Sami, A., Xie, Y.F., Tao, M. and Xiang, J. (2015) HER2-Specific Vaccines for HER2-Positive Breast Cancer Immunotherapy. World Journal of Vaccines, 5, 106-128. 


\section{Keywords}

\section{HER2, Breast Cancer, DNA, Peptide, Dendritic Cell, Vaccine}

\section{Introduction}

Growth factors are essential for the development, growth, and homeostasis of multicellular organisms. The epidermal growth factor (EGF) belongs to group of molecules that stimulate four receptor tyrosine kinases of the human EGF receptor (HER) family [1] [2]. The HER family is made up of four receptors (EGFR/HER1, HER2, HER3, HER4) and expressed as a transmembrane receptor with a functional tyrosine kinase activity [1] [2]. These structurally related receptors are single chain transmembrane glycoproteins that consist of an extracellular ligand-binding ectodomain, a transmembrane domain, a short juxtamembrane section, a tyrosine kinase domain and a tyrosine-containing C-terminal tail [2]. Binding of soluble ligand to the ectodomain of the receptor promotes homo- and heterodimer formation between receptors [2]. The HERs are responsible for transducing extracellular signals by activating intracellular messengers or directly through receptor translocation into the nucleus to mediate cell—cell interactions. [3].

These receptors interact with a family of 12 polypeptide growth factors, the binding of which stimulates both homodimeric and heterodimeric interactions between family members leading to auto phosphorylation of a number of cytoplasmic tyrosine residues [4]. These phosphorylated tyrosine residues serve as docking sites for many adaptor and signalling proteins that culminate in a number of physiologic and pathologic changes in cellular behaviours including cell growth, survival and differentiation through inter-linked signal transduction involving activation of the PI3K/Akt and the Ras/Raf/MEK/MAPK pathways [4]. It has been noted that the location of the receptor also confers advantages for activation. For instance, the HER family is located on the epithelial cells lying in proximity of and basolateral to the immature connective tissue that consists of cells embedded in extracellular matrix (the mesenchyme); this relationship therefore provides these receptors an advantage that aids signal transduction between the epithelia cells and the mesenchyme [1] [3] [4]. In addition, the mesenchyme also serves as a store keeper of ligands, for instance, neuregulin (NRG) which is predominantly found within the mesenchyme, has the potential to bind to HER3 and HER4 to induce signalling [2] [3].

Aberrant tyrosine kinase activity of HER family members can result in unregulated growth stimulation and tumorigenesis in various tumour types, including breast, lung, brain, head and neck, and colon tumours [3] [5]. This can occur through a range of mechanisms, including over expression (often due to gene amplification), point mutations, partial deletions and autocrine ligand-receptor stimulation, hence, over expression and/or mutation can lead to ligand-independent activation as well as to increased activation following engagement with the ligand [1]-[3].

\subsection{Signalling through HER Receptors}

As mentioned earlier, the four members of HER family are the HER1, HER2, HER3 and HER4. The binding of a ligand to the extracellular lobe of HER1, HER3 or HER4 induces homodimer formation, however, while homodimerization of HER3 does not result in any form of activation due to its lack of kinase domain [5] [6], a homodimerization with HER1 or HER4 often leads to a weak signalling activation [1] [6]. The HER2 protein has no identified ligand and is activated through the heterotypic interaction of its extracellular domain with that of other EGFR receptors such as HER1, HER3 or HER4 [7] [8], resulting in cell growth, migration and differentiation via a signal transduction cascade mediated by the activation of P13K/Akt and the Ras/Raf/MERK/MAPK pathways [4] [9]. Furthermore, whenever there is HER2 over expression, there would be a preference for heterodimerization formation, but even low expression of HER2 may result in weak signalling and activation [5] [10]. Evidence from a number of published studies points to the fact that some particular features associated with HER2 make it a unique stronghold for increasing epithelial cancers progression and treatment resistance. These include (I) its lack of identifiable ligand; (II) always maintaining the open conformation, thereby allowing for increased chance for dimerization; (III) location at basolateral face of the epithelium thereby easy heterodimer formation with other HER families, which often stimulated by ligands secreted by the stromal cells; and (IV) lack of transacting compounds with the ability of HER2 targeting at the location [11] [12]. 


\subsection{HER2-Positive Breast Cancer}

Since HER2 has $80 \%$ sequence homology to the rat neu gene-coded protein neu, originally detected on rat neuroblastoma cells [13], the proto-oncogene HER2 can thus also be called HER2/neu. HER2 over expression occurs in approximately 20\% - 30\% of breast cancers [14]-[16]. Even when the cancer progress on HER2-specific immunotherapy, the breast cancers still rely on HER2 signaling and its downstream pathways; this is consistent with the oncogene addiction model [17]. Slamon first reported that the amplification of HER2 oncogene correlated with shorter time to relapse and lower survival in breast cancer patients [18]. Later, HER2 gene amplification in breast cancer was recognized in many experimental and clinical studies; it was often associated with increased cell proliferation, cell motility, tumor invasiveness, progressive regional and distant metastases, accelerated angiogenesis, and reduced apoptosis. The validation of the general prognostic significance of HER2 gene amplification and protein over expression have been discussed in more than 100 published studies involving 39,730 patients; data from those studies points to an overall HER2-positive rate of $22.2 \%$ and a mean relative risk for overall survival (OS) of 2.74 [14]. Importantly, HER2 amplified breast cancers appear to have a higher propensity for worse prognosis compared with non-amplified breast cancers, hence the amplification is an early event and defines a subtype of breast cancer. HER2-amplified breast cancers have biologic characteristics that distinguish them from other types of breast cancers. These include increased sensitivity to certain cytotoxic chemotherapeutic agents, resistance to certain hormonal agents and increased propensity to metastasize to the brain. Clinically, HER2 status in breast cancer is currently one method of molecular classification to determine biology and choice of therapy [14]. In early 1990s, Genentech developed trastuzumab (Herceptin) from Chinese hamster ovary cells [19]. Trastuzumab is the humanized monoclonal antibody against the extracellular domain of HER2 [20]. Clinical trials demonstrated that OS was superior in patients with advanced HER2-positive breast cancer treated with trastuzumab compared to the non-trastuzumab arm, with a median survival of 25.1 months versus 20.3 months, respectively $(P=0.046)$ [18] [21]. Although trastuzumab (Herceptin) and receptor tyrosine kinase inhibitors like lapatinib are effective against HER2-positive breast cancers, breast cancer patients sooner or later develop resistance to the treatment. This suggests an urgent need for designing an alternative treatment that can effectively control tumor progression.

\section{Methods}

This review summarizes the development and current trend in experimental and clinical investigations in HER2positive breast cancer using HER2-specific vaccine and immunotherapy. The search strategy employed consisted of relevant English language studies from January 1999 to September 2014, which were identified through PubMed, Medline, EMBO and Google Scholar. Following key words were used for computer-based literature search: breast cancer, immunotherapy, HER2-peptide vaccine, HER2-DNA vaccine, HER-DC vaccine, HER2 vaccine, and HER2/neu, T-cell vaccine, methods of vaccine construction, plasmid cancer vaccine, electroporation and cancer etch. When appropriate, relevant medical subject headings were also searched for within a database and also added to the search term list. Additional studies were identified from reference lists of retrieved papers and review articles. In addition, data from recently reported clinical trials were also included.

\section{HER2 DNA Vaccine}

\subsection{Introduction}

An effective cancer vaccine is the one that activates the immune system to react against tumor-associated antigens (TAAs) and, in some cases, overcomes immunological tolerance to such TAAs. Cancer cells attempt to become invisible to $\mathrm{T}$ cells by decreasing the major histocompatibility complex (MHC) glycoproteins expression on their cell membrane, and at the same time, suppress immune reactivity via the direct release of transforming growth factor (TGF)-beta, IL-10, and indoleamine 2, 3-dioxygenase (IDO), and through the activation of such secretions in myeloid-derived suppressor cells, tumor-associated macrophages, and dendritic cells (DCs) [22]. Advances in cancer biology, an increasing knowledge of immune mechanisms and the availability of new animal models that recapitulate several human cancers, have all helped to elucidate the critical issues that influence the efficacy of the immune system's attack on cancer including HER2-positive breast cancer [23]-[25]. Today, some new molecular strategies have been developed that are able to enhance cancer vaccines' ability to stimulate immune responses against established tumors, besides hampering cancer progression when used at 
early stages of the disease. Here, we focus on the current developments in HER2 DNA vaccines.

Progress in recombinant DNA technology allows for the construction of HER2 DNA vaccines that encode selected tumor antigens (Ags) in their native forms or in a modified molecular format, alone or together with other molecules, to direct and to amplify the desired effect or pathways. DNA vaccines are simple circles of DNA, principally derived from bacterial plasmids, which contain cDNA coding for the target Ag, a strong viral promoter to drive the Ag expression in mammalian cells and a polyadenylation signal for transcription termination [26]. DNA vaccines offer distinct advantages over other vaccine prototypes. They are stable, relatively inexpensive and simple to purify in large quantities. The DNA vaccine is commonly delivered either via the biolistic system or via simple intradermal or intra-muscular (i.m) injections which are commonly followed by a short in vivo electric pulse (electroporation) to enhance DNA transfection by inducing transient biological membrane permeability [26] [27]. Once DNA vaccines enter mammalian cells, antigen synthesis and presentation occur [28] [29]. Professional antigen-presenting cells (APCs), such as dendritic cells (DCs), are able to present the transcribed and translated antigen in the proper context of MHC and costimulatory molecules, eliciting both cellular and humoral immune responses. In addition, bacterial plasmids, unlike mammalian DNA, are rich in unmethylated CpG dinucleotides which activate the innate immune response by the binding with Toll-like receptor 9 expressed on B cells and APCs. Thus, DNA vaccines are effective even when administrated without adjuvants [28] [29]. However, chemokines and cytokines such as granulocyte-macrophage colony-stimulating factor (GM-CSF) are commonly employed to improve protection by DNA vaccines [28]-[30]. Currently, the method of administration has evolved progressively to include both HER2 and cytokine DNA administered together by electroporation after regulatory T-cell depletion [29]. This approach makes HER2 DNA vaccine a promising clinical vaccine candidate [26].

\subsection{HER2 DNA Vaccine Constructs}

A number of human ErbB-2 (E2) DNA constructs have been designed to encode recombinant HER2 proteins that should be free of tyrosine kinase activity and traffic to specific sub-cellular compartments of cell. Four major forms of HER2 constructs are recognized, of which, the pE2A that encodes the full length HER2 with a single substitution of aa Lys753 to Ala753 to remove the ATP binding lysine residue, pE2TM encodes the signal peptide, extracellular and transmembrane domains without the intra-cellular domain (ICD), the psecE2 that encodes the N-terminus aa 1 - 505 of the extracellular domain as a secreted protein [29] [31] [32]. These three constructs induced both cellular and humoral immune responses and strong protective immunity in BALB/c and C57BL/6 mice [26] [29] [33]. The fourth construct is the pcytE2, with truncated ER signal peptide, that encodes the synthesis of a full-length, short-lived cytoplasmic protein, promptly degraded by the proteasome-immunization. This construct activates CD8 T cells without humoral response [34]. During the early development of HER2 DNA vaccines, adjuvant were not administered concurrently with the vaccine, however, further refinement in research showed that addition of adjuvant like pGM-CSF followed by electroporation at the vaccination site significantly enhanced gene expression and immune reactivity [29] [35].

\subsection{Experimental Evidence for HER2 DNA Vaccine}

The earliest preclinical study for potential application of DNA based HER2 vaccine for treatment of HER2positive breast cancer was reported by Chen et al. [36]. Using DNA expression vectors encoding the full-length neu cDNA (designated pNeuN) responsible for neu extracellular domain (pNeuE), or the neu extracellular and transmembrane domains (pNeuTM) that were transfected to the 293 cell lines to investigate whether i.m. injection of either of these plasmids DNA vaccine could induce protective immunity in FVB/N breast cancer mice model, the author showed that i.m. injection of pNeuTM or pNeuE, induced protective immunity against a subsequent challenge with Tgl-1 cells in the FVB/N mice, suggesting that HER2/neu DNA vaccine including plasmid pNeuTM might be an effective therapeutic approach in breast cancer [36]. This means that DNA expression vectors encoding soluble or membrane-bound forms of HER2/neu lacking the cytoplasmic kinase domain can be effective in inducing protective antitumor immunity

Subsequently, several DNA vaccines that encode a modified human HER2 protein without tyrosine kinase activity were developed including three main constructs, for example, (a) pE2A which encodes a full length HER2 in which Lys753 has been substituted by Ala to remove the ATP-binding Lys residue, (b) pE2TM which encodes the HER2 signal peptide, extracellular and transmembrane domains but not the intracellular one, and (c) 
psecE2 which encodes the N-terminal portion (aa 1 - 505) of ECD as a secreted protein [31]. The authors reported that all three DNA constructs induced both cellular and humoral immune responses against HER-2 molecule leading to in vivo tumor protection. In that study, BALB/c mice were immunized 3 times at 2-week intervals by i.m. injection in the thigh with $100 \mu \mathrm{g}$ of the DNA vaccines. A complete inhibition of tumor growth was found in the mice received the DNA vaccine

Another study in which 3 different human HER2-specific DNA vaccines were constructed found that HER2-specific cytotoxic T lymphocytes (CTLs) were detectable after immunization, and mice immunized with the HER2-specific DNA vaccines were resistant to the tumor challenge [32]. Specifically, the author showed that cytoplasmic HER2 DNA vaccine induced anti-tumor CTLs, but not humoral immune response, confirming the feasibility of eliciting individual effectors by targeted DNA vaccines. It is generally known that a depletion of $\mathrm{CD}^{+}$, but not $\mathrm{CD}^{+} \mathrm{T}$ cells often results in reduced anti-tumor immunity, indicating CTLs as the effector cells [32]. Pupa and colleagues in 2005 using plasmid DNA vectors encoding the full-length (VR1012/ HER2-FL) or only the extracellular and transmembrane domains (VR1012/HER-2-ECD-TM) of HER2 proto- oncogene to vaccinate HER-2/neu transgenic mice (N202) engineered to over express the rat neu proto-onco- gene product (r-p185(neu)), reported an inhibition of mammary carcinoma development in HER2 transgenic mice through induction of autoimmunity by xenogeneic DNA vaccination. In addition, experimental data demonstrated that both the full-length and the deleted DNA vaccines significantly $(P=0.0001$ and $P=0.06$, respectively) prevented and delayed HER2-driven mammary carcinogenesis more actively than the empty vector (VR1012/EV) [33]. Although DNA vaccine holds a great potential for cancer immunotherapy, effective balance of auto-immunity and conferment of long-lasting antitumoral immunity sufficient to induce durable responses in cancer patients remain to be achieved. Considering the pivotal role of DCs in the antigen processing and presentation in addressing the aforementioned challenge, a recent study constructed a DC-targeting DNA vaccines by fusing HER2 ectodomain Ag to single-chain Ab fragment variable-region ( $\mathrm{scFv}$ ) from NLDC-145 antibody specific for DC-restricted surface molecule DEC-205 (scFv $\left.\mathrm{sLDC}^{\mathrm{NL}-145}\right)$, and explored its antitumoral efficacy in mouse breast cancer models [37]. Using in vivo targeting assay, the authors demonstrated that scFv ${ }^{\mathrm{NLDC}-145}$ specifically delivered DNA vaccine-encoded Ag to DCs, and reported that vaccination with $\mathrm{SCFv}^{\mathrm{NLDC}-145}$-HER2 markedly promoted HER2-specific cellular and humoral immune responses, conferring long-lasting CTL memory which resulted in effective protection against challenge of HER2-positive D2F2/E2 breast tumor [37]. Hence, when a temporary depletion of regulatory $\mathrm{T}$ (Treg) cells by low-dose cyclophosphamide was combined with vaccination with $\mathrm{scFv} \mathrm{v}^{\mathrm{NLDC}-145}$-HER2, regression of established D2F2/E2 breast tumor occurred which significantly retarded the development of a spontaneous mammary carcinomas in transgenic BALB-neuT mice. This suggests that DC-targeted DNA vaccines with direct delivery of HER2 to DCs could improve HER2-specific cellular and humoral immune responses and could elicit an impressive therapeutic antitumoral activity by overcoming immunotolerance for HER2 Ag.

\subsection{HER2 DNA Vaccine; Balancing Immunity with Autoimmunity}

HER2 DNA vaccines have shown promising activity in human HER2 or rat neu transgenic mice; however, immunotolerance to the tumor-associated self-antigen continues to be a major challenge. Many experimental studies have attempted overcoming immunotolerance to the tumor-associated self-antigen by immunizing with heterogenous xenogeneic Ags, i.e. using primate or monkey HER2 or other related model. The heterogenous xenogeneic Ags often share common or cross-reactive epitopes with self-antigens to overcome immune tolerance and trigger cell-reactive T cells. For example, human or mouse tyrosinase DNA is included in a current DNA cancer vaccine approved for treating melanoma in dogs in clinical setting.

Previous studies have shown that treating a transgenic mice with xenogeneic DNA with plasmid DNA vectors encoding the full-length HER gene (VR1012/HER-2-FL) produced autoreactive antibodies targeting mouse (m)p185(neu) that resulted in impaired function of the lactating mammary gland and accelerated involution of the gland after weaning [33]. This suggests HER2-specific DNA vaccine can be improved to enhance or block immunotolerance by using xenogeneic DNA antigen [29] [35]. For example, DNA coding for chimeric rat/human HER2/neu was investigated as a tool to break immunotolerance and unresponsiveness of $\mathrm{T}$ cells from patients with HER2-overexpressing tumors [38] [39]. The authors demonstrated that chimeric constructs encoding rat/ human HER2/neu fusion proteins induced specific and sustained proliferation and IFN- $\gamma$ production by CD4 ${ }^{+}$ and $\mathrm{CD}^{+} \mathrm{T}$ cells. It appears that the chimeric plasmids also contribute to overcoming tumor-induced T-cell 
dysfunction [39]. A HER2 DNA vaccine that expresses both human HER2 and heterologous rat neu sequences in separate plasmids or as single hybrid constructs that encode HER fusion proteins, effectively primed immune effector cells in HER2 transgenic (Tg) mice and resulted in rejection of HER2-positive tumors; this suggested that a combination of heterologous and self-antigens e.g. rat neu and human HER2 may enhance antitumor immunity [38]. It has been demonstrated that a new vaccination regimen that has heterologous rat neu together with self HER2 or a hybrid construct significantly improved anti-HER2 immunity and protective activity in HER2 Tg mice of three different genetic backgrounds with documented evidence of epitope spreading [38]. This means that a strategy of combining heterologous antigen with self-antigens could produce a potent DNA vaccine that can overcome immunotolerance, and could be applicable to other TAAs.

\subsection{HER2 DNA Vaccine; Immunotolerance, the Role of Regulatory T Cell Deletion}

Treg cells, which often characterized by the expression of the transcription factor FoxP3 as well as CD4 and CD25, play a key role in the regulation of adaptive immunity [40]. Tregs can suppress immune responses by secreting suppressive cytokines like TGF- $\beta$ and IL-35 [40]. Tregs are a potential barrier to develop productive immune therapies for HER2-positive cancer and represent an attractive target for enhancing antitumor immunity. For instance, evidence has shown that removal of $\mathrm{FoxP}^{+} \mathrm{CD}^{2} 5^{+}$Tregs enabled autoimmune-resistant mice to develop autoimmunity and abrogated induced-tolerance in vivo, and repeated blockade of Tregs and/or costimulation of $\mathrm{T}$ effectors lad to different autoimmune diseases [41]. It appeared therefore that HER2 immunity might be under the control of $\mathrm{CD} 25^{+}$Treg and can be amplified by Treg depletion strategies. For instance , in wild-type thyroiditis-resistant BALB/c mice, when Treg cells were removed, the neu ${ }^{+}$TUBO (transplantable carcinoma cells lines) tumors underwent regression, and both immune responses to rat neu and mouse thyroglobulin (mTg) increased [42] [43]. In addition, vaccination with HER2 DNA in combination with pre-treatment with anti-CD25 antibody (Ab) to remove CD25 ${ }^{\text {hi }}$ Treg cells before vaccination, significantly improved protection from tumor challenge in F1 HER2 Tg mice and resulted in elevation in levels of HER2 IgG1, IgG2a and IgG2c Abs and IFN- $\gamma$-producing T cell responses [29].

Results from a similar study that worked on refining or improving the immunotolerance challenge with HER2 DNA vaccine have also been reported [34]. A susceptibility allele associated with thyroid is HLA-DRB1*0301 (DR3) was introduced into HER2 transgenic mice to simulate human immune reactivity to HER2 and thyroglobulin. The author tested the balance between tumor immunity and autoimmunity in neu-transgenic BALB NeuT female mice, which developed spontaneous mammary tumors and reported that in BALB NeuT mice carrying neu ${ }^{+}$TUBO tumor s.c., self tolerance or immunotolerance to neu was overcome by three-time electrovaccination with pneuTM following Treg depletion with anti-CD25 Ab; this led to tumor regression, whereas vaccination or Treg depletion alone did not induce significant immune responses, or tumor regression [34]. In particular, 10 mice treated with anti-CD25 Ab and DNA vaccination, their TUBO tumors regressed completely and there was significant anti-neu $\mathrm{Ab}$ and IFN- $\gamma$-producing $\mathrm{T}$ cells, indicating that tumor rejection in neu-tolerant mice was mediated by substantial immunity, however, tumor regression induced by Treg depletion and DNA vaccination was found to exacerbate autoimmunity, which warrants close monitoring during immunotherapy [34]. Taken together, the fact that HER2 expression in the thymus and its over expression in the mammary gland, often lead to $\mathrm{CD}^{+} \mathrm{T}$ cell clones that can react at high avidity with HER2 epitopes to be deleted, resulting in immunotolerance to HER2; however, there is clear evidence that BALB-HER neuT mice with Treg depletion combined with HER2 DNA vaccine has a pool of low-moderate avidity CD8 ${ }^{+}$T cells bearing TCR repertoire reacting against HER2 dominant peptide and blocked tumor progression at stages in which the vaccine alone was ineffective [44].

\subsection{HER2 DNA Vaccines; Clinical Studies}

HER2 DNA-based vaccines have currently entered into different phases of clinical trials. For example, in 2009, Emens and colleagues [45] conducted a phase I clinical trial to determine the safety of HER2-positive, allogeneic, GM-CSF-secreting tumor vaccine in 28 patients with metastatic breast cancer. Patients received three monthly immunizations with a boost 6 to 8 months from study entry. That study found that immunotherapy with an allogeneic, HER2-positive, GM-CSF-secreting breast tumor vaccine alone or with cyclophosphamide (CY) and doxorubicin (DOX) was safe and induced HER2-specific immunity in patients with metastatic breast cancer [45]. The result from a clinical trial which involved vaccination with a plasmid DNA encoding HER together 
with low doses of GM-CSF and IL-2 in patients with HER2-positive metastatic breast carcinoma, indicated that HER2-pDNA vaccination in conjunction with GM-CSF and IL-2 administration was safe, well tolerated and induced long-lasting cellular and humoral immune responses against HER2 in such patients [46]. No acute toxicity, autoimmunity or cardiotoxicity were observed after administration of HER2 DNA in combination with GM-CSF, IL-2 and trastuzumab. Immediately after all cycles of vaccination, a significant increase of MHC class II restricted T-cell responses to HER2 was detected at long term follow-up [46]. Interestingly, it was demonstrated that HER2 DNA vaccination induced and boosted HER2-specific Abs that could be detected for several years after the last vaccine administration in a subgroup of patients [46].

Another phase I clinical trial that was conducted in June 2007 recruited patients with HER2 over-expressing metastatic breast cancer who were treated with one or two lines of chemotherapy with or without trastuzumab [47]. The vaccine used in the study was the MVA-BN-HER2 formed by a non-replicating viral vector encoding a truncated form of HER2 protein (without its ICD) and two universal Th epitopes of the tetanus toxin were used to boost the immune system. Similarly, some other clinical trials used either DNA coding for the HER2 intracellular domain cloned into the pNGVL3 plasmid or adenovirus-inserted rat HER2 DNA; results of such studies were yet to be published at the time of writing this work. Most recently, result from a multicenter phase I trials involving adult cancer patients $(n=33)$ with stage II-IV disease has been published [48]. In that study, patients were vaccinated with V930 alone, a DNA vaccine containing equal amounts of plasmids expressing the extracellular and trans-membrane domains of human HER2, and a plasmid expressing CEA fused to the B subunit of Escherichia coli heat labile toxin, or a heterologous prime-boost vaccination approach with V930 followed by V932, a dicistronic adenovirus subtype-6 viral vector vaccine coding for the same antigens. The author demonstrated that use of the V930 vaccination with electroporation alone or in combination with V932 was well-tolerated without any serious adverse events [48]. The most common vaccine-related side effects were injection site reactions and arthralgias, however, no measurable cell-mediated immune response (CMI) to CEA or HER2 was detected in patients. Of note was that a significant increase in both cell-mediated immunity and antibody titer against the bacterial heat labile toxin were observed upon vaccination; this clearly suggested that DNA cancer vaccine including V930 vaccination alone or in combination with for example V932 was well tolerated without any vaccine-related serious adverse effects, and was able to induce measurable immune responses [48].

\subsection{HER2 DNA Vaccine; Clinical Trials in Progress}

Documented evidence indicates ongoing clinical trials with other forms of HER2 DNA vaccine at various stages ranging from phase I-III which are either recruiting patients or near completion at the time of writing this review, and involving patients with stage II, III or IV HER2-positive breast cancers [47]. Some of these trials are conducted by Bavarian Nordic's subsidiary BN Immunotherapeutics (BNIT), MERK, Ontario Clinical Oncology Group and Hutchinson Cancer. The various HER-2-specific vaccines undergoing clinical trials are DNA-based vaccine coding for the HER2 extracellular domain including two universal epitopes from the tetanus toxin delivered through non replicating vaccine virus in HER2-positive metastatic breast cancer patients; plasmid DNA coding for the HER2 peptide (V930) in stage II/III/IV breast cancers patients; DNA coding for the HER2 intracellular domain delivered through pNGVL3 plasmid in stage III/IV breast cancer and DNA coding for the HER2 intracellular domain plus GM-CSF delivered through pNGVL3 plasmid in stage III/IV breast cancer [47]. Three clinical trials, using either DNA coding for the HER2 intracellular domain cloned into the pNGVL3 plasmid or adenovirus-inserted rat HER2 DNA, are currently recruiting participants as at the time of writing this work.

\subsection{Challenges in HER2 DNA Vaccine}

Many setbacks have been reported that challenge of the applicability of DNA-based vaccines for cancer immunotherapy. These includes the development of tolerance, age-related reduced effectiveness due to the existence of age-related defects in activation of specific immune responses (immunosenescence), for instance, an intramuscular DNA vaccination against HER2 resulted in a lower effectiveness in older mice with a reduced number of objective responses in aged animals [49]; low immunogenicity of DNA vaccine [35] and the vaccine delivery system, i.e. i.m., intravenous (i.v), etc. Some authors have suggested that intramuscular delivery of plasmid DNA vaccine by electroporation improved response [50]. Another experimental study in which rat neu oncogene was embedded into the genome of virgin transgenic BALB/c mice (BALB-neuT) to provoke the development of an invasive carcinoma in each of their 10 mammary glands demonstrated that i.m. vaccination with 
DNA plasmids (coding for the extracellular and transmembrane domains of the protein product of the HER2 oncogene), when the mice already displayed multifocal in situ carcinomas, temporarily halted the neoplastic progression, however, all mice developed tumor by week 43. Nevertheless, a progressive clearance of neoplastic lesions and complete protection of all 1-year-old mice occurred when the same plasmids were electroporated at 10-week intervals [51]. Furthermore, the author showed that that tumor clearance depended on the combination of antibodies and IFN-gamma-releasing T cells, suggesting that appropriate vaccine can effectively inhibit the progression of multifocal preneoplastic lesions [51]. Put together, DNA vaccine model represents a promising, practical, and effective way to elicit immune responses against HER2, however, when translated from murine models to large animal models or clinical human use, there is often lost potency. This problem has occupied the focus of many scientists across different laboratories to improve DNA vaccines, making it capable of inducing strong effector and memory CTL responses against HER2 through the use of adjuvant molecules.

\section{HER2-Specific Peptide Vaccine}

\subsection{Short Peptide Vaccine}

$\mathrm{CD}^{+}$cytotoxic $\mathrm{T}$ cells recognize their target Ag peptides of $8-10$ amino acids presented by MHC class I complexes at the cell surfaces. There are three highly polymorphic isotypes in HLA class I: HLA-A, HLA-B and HLA-C, which are recognized by CTLs. The first peptide vaccine that was able to induce a CTL response in vivo was reported in 1990 [52]. Since then, pre-clinical and clinical vaccination studies involving peptide-based vaccines have employed formulations comprised of short peptides that match the exact, minimal sequences of MHC class I-binding $\mathrm{CD8}^{+} \mathrm{T}$ cell epitopes [53]. These peptides have exact MHC class I binding epitopes and used as short peptide or minimal peptide vaccines [54]. A number of studies in multiple mouse models have shown that prior immunization of mice with vaccines comprising minimal CTL epitopes can protect against outgrowth of subsequently transplanted tumors, this lead to the testing of this concept in a considerable number of clinical studies involving cancer patients [55]. Subsequent report showed that vaccination with short peptides was associated with significant immunological tolerance of the immunizing antigens, and did not induce significant immunity [56]. By using a highly immunogenic ovalbumin (OVA) CTL peptide as a model peptidebased vaccine, Bijker et al. investigated suboptimal performance of minimal CTL peptide vaccines to allow full optimization of peptide vaccination [56]. The study showed that injection of the minimal MHC class I-binding $\mathrm{OVA}_{257-264}$ peptide transiently activated $\mathrm{CD}^{+}$effector $\mathrm{T}$ cells, which eventually failed to undergo secondary expansion or to kill target cells, hence by adding more peptides to increase the length of the vaccine, it was demonstrated that there was complete failure to induce memory cells [56]. This highlights why such vaccines rarely elicit truly therapeutic $\mathrm{T}$ cell immunity capable of clearing pre-existing tumors. It has been shown that injection of short peptides leads to the exogenous loading in vivo of MHC class I molecules on all cells that have such molecules, including $\mathrm{T}$ and $\mathrm{B}$ cells; these $\mathrm{B}$ and $\mathrm{T}$ cells circulate and therefore also arrive in lymph nodes throughout the body in the absence of immunostimulatory adjuvants and lead to immunological tolerance because $\mathrm{T}$ and $\mathrm{B}$ cells, in contrast to properly activated DCs, lack the co-stimulatory molecules require for appropriate effector cytotoxic T (Tc) cell generation [54].

Furthermore, it has been shown that minimal CTL peptide vaccine induced strong CTL-mediated immunity in mice due to the fact that this small peptide contained a helper $\mathrm{CD}^{+} \mathrm{T}\left(\mathrm{T}_{\mathrm{H}}\right)$-cell epitope that induced a concomitant $T_{H}$ response [57] [58]. Studies to explore other mechanism of improving peptide vaccine in cancer immunotherapy lead to the discovery that a longer than the minimal MHC class I-binding sequence supplemented with $\mathrm{T}_{\mathrm{H}}$ peptides could induce better responses [54] [57] [58]. It is known that $\mathrm{CD} 4^{+} \mathrm{T}_{\mathrm{H}}$ cells deliver help to $\mathrm{CD}^{+} \mathrm{T}_{\mathrm{c}}$ cells by fully activating DCs through the CD40-CD40L signalling pathway, as well as by the secretion of interleukin 2 (IL-2) [59]. Indeed, co-injection of both minimal $T_{c}$ peptides and $T_{H}$ peptides not only prevented the induction of $T_{c}$ tolerance but also increased the magnitude of the $T_{c}$ responses, and was able to confer protection in mice against an otherwise lethal tumour challenge [60] [61].

\subsection{Short/Minimal Peptide Vaccine Design}

It is generally accepted that effective DC-activation is easily accomplished using some molecularly defined innate receptors including the Toll-like receptor (TLR) family and/or adaptive immunity receptors such as CD40. For example in several mouse models, agonists of TLR3, TLR4, TLR7 and TLR9 significantly enhanced the magnitude and efficacy of tumour-specific $\mathrm{T}_{\mathrm{c}}$ responses [62]. The deoxycytidyl-deoxyguanosin oligodeoxynu- 
cleotides (CpG ODNs) are known to trigger Toll-like receptor 9 signalling, resulting in dendritic cell maturation that can enhance immunogenicity of peptide-based vaccines in mice [63]. In humans, the use of CpG 7909 (a TLR9 ligand) not only enhances the magnitude of $T_{c}$ response but also the activation status to a minimal $T_{c}$ peptide vaccine [63]. Consequently, the administration of CD40 agonist Abs in vivo to activate DCs considerably enhances the efficacy of a peptide-based anti-tumour vaccine in mice, thus combinations of CD40 agonist Ab with TLR agonists display a remarkable synergism in DC activation [64] [65]. This suggests that inclusion of different adjuvants in peptide vaccine can modify therapeutic responses.

\subsection{Synthetic Long Peptide Vaccine}

Synthetic long peptide vaccine is another method to improve immunogenicity and efficacy of peptide vaccine.. This involves conjugation of minimal $\mathrm{T}_{\mathrm{H}}$ and $\mathrm{T}_{\mathrm{c}}$ peptides to form a single linear hybrid peptides, this indicates that presentation of both $T_{H}$ and $T_{c}$ peptide epitopes is more efficient than when the two epitopes were delivered as a mix. A direct linkage of $\mathrm{T}_{\mathrm{H}}$-peptide with CTL epitope increases the vaccine efficacy. Furthermore, the conjugation of a TLR ligand to a $T_{c}$ epitope improves vaccine potency, due to the fact that TLR-conjugated peptides are efficiently taken up by professional APCs [66]. It has been demonstrated that, using a mouse model, synthetic vaccines composed of a TLR ligand, a helper T-cell epitope and a $T_{c}$ epitope induced a stronger immunity against tumours [66] [67]. This is known as a hybrid peptide vaccine and is formed by covalently linking a TLR ligand with a $\mathrm{T}_{\mathrm{H}}$ peptide and a $\mathrm{T}_{\mathrm{c}}$ peptide. Evidence from published studies reveal that peptide vaccine constructs lacking the $\mathrm{T}_{\mathrm{H}}$ epitope are less effective

Lastly, an increase in the length of peptide used for constructing or designing vaccine has been shown to significantly affect the magnitude of the induced $\mathrm{CD}^{+} \mathrm{T}$-cell response. For instance, long peptides of 22 - 45 amino acids in length containing either a human papillomavirus (HPV)-derived, an adenovirus-derived or a modified ovalbumin-derived cytotoxic $T\left(T_{c}\right)$ epitope resulted in more robust and effective $T_{c}$ responses than vaccination with a minimal MHC class I-binding peptide vaccine [68]. This suggests that long peptide vaccine may induce an effective anti-tumour response with the capacity to eradicate established tumours in mice. When a long synthetic peptide containing an ovalbumin cytotoxic T-cell epitope was chemically conjugated to two different TLR-Ls, the TLR2 ligand, or the TLR9 ligand CpG, there was a rapid and enhanced uptake of both types of TLR-L-conjugated peptide in DCs which resulted in an enhanced antigen presentation, a process that was dependent on endosomal acidification and proteasomal cleavage [66]. Moreover, when subjected to conditions that precluded T-cell help, a single vaccination with a long peptide vaccine induced significantly higher $\mathrm{CD}^{+} \mathrm{T}$-cell responses in MHC class II knockout mice and in CD40 knockout mice than a minimal $\mathrm{T}_{\mathrm{c}}$ peptide [54] [66] [68]. Therefore, it appears that both physical linking of $T_{H}$ and $T_{c}$ epitopes and conjugation of TLR ligands to MHC class 1 peptide vaccine increase the size of the ultimate peptide used and as such may improve the $T_{c}$ response through the mechanism that explains the difference between long and minimal $T_{c}$ peptides. The group of peptides vaccines with these modifications are collectively known as synthetic long peptide vaccines.

\subsection{How Peptide Vaccines Work}

It is deducible that immunization with minimal $\mathrm{T}_{\mathrm{c}}$ peptide epitopes allows for direct binding to major histocompatibility complex (MHC) class I molecules on DCs in the submucosa; others can travel to the draining lymph node where the peptide epitopes can bind exogenously to DCs, $\mathrm{T}$ cells and B cells, these collectively result in the expansion of antigen-specific $\mathrm{CD}^{+}$memory $\mathrm{T}(\mathrm{Tm})$ cells [66]. However, such Tm cells do not possess strong effector function and the response is transient. Recognition of cognate Ag presented by either $\mathrm{T}$ or $\mathrm{B}$ cells will lead to an abortive proliferative response and death of the responding $\mathrm{CD}^{+} \mathrm{T}$ cells [66]. Inclusion of a $\mathrm{T}_{\mathrm{H}}$ peptide in the vaccine improves efficacy by enhancing presentation of both the $T_{c}$ peptide and the $T_{H}$ peptide by DCs, causing stimulation of specific $\mathrm{CD}^{+}$T-helper cells and induces a signal that allows DCs to endow the $\mathrm{CD}^{+} \mathrm{T}$ cells with a licence-to-kill signal and to become full effector cells. However, the use of overlapping peptide epitopes ensures that any DCs that have taken up Ag peptide will stimulate both CD $4^{+}$helper $\mathrm{T}$ cells and $\mathrm{CD}^{+} \mathrm{T}$ cells and this result in stronger and more effective immune responses [56].

\subsection{HER2 Peptide Vaccine; Clinical Evidence}

There is a large amount of data available on HER2 peptide vaccines [69] [70]. HER2 peptide-based vaccines are used to specifically induce generation of Abs, CTLs and $\mathrm{T}_{\mathrm{H}}$ cells using antigenic epitopes derived from TAAs 
[69] [71]. The first investigation on peptide vaccine was in 1990s and was based on single-epitope peptides, emulsified with clinical graded adjuvants or pulsed on DCs, restricted by a single HLA class-I type [71] [72]. Emerging evidence indicates the availability of multiple or long multivalent peptides which are currently being studied to understand their potential to elicit stronger and more complete responses, including HLA class-II restricted T-helper cells [71] [73]. Currently, a number of peptides from the HER2 protein have been designed as HER2 peptide vaccine with various peptide lengths. These include E75 (amino acids aa: 369 - 377), GP2 (aa: 654 - 662) peptides, which are both HLA-A2/A3-restricted, and the hybrid AE37 (aa: 776 - 790 + Ii-Key modification of a four-amino acid [LRMK] addition to increase its potency). This peptide is promiscuous for HLA class II binding, a peptide that stimulates CD4 T-helper cells and appears to have the ability to generate long-term peptide-specific immune responses [70]. These peptides are located on the extracellular domain (E75), transmembrane portion (GP2), and intracellular domain (AE37) of the HER2 protein. Potential advantages of peptide-based vaccines are further discussed below

\subsection{The E75 HER2 Peptide (Amino Acids AA: 369-377) Vaccine}

Several immunogenic peptides from HER2 sequence recognized by CTLs have been described [71]-[73]. Among them the E75 (HER2, 369 - 377), one of the widely reported HER2 peptide vaccine known as Nelipepimut-S which is a HLA class-I restricted peptide that stimulates CTLs, is the most studied. The peptide is derived from the extracellular domain (ECD) of HER2 and is characterized by human leukocyte antigen (HLAA2/A3) restriction [74]. HLA-A2 molecules are expressed in about $40 \%-50 \%$ of Caucasian population, and are reported to effectively present suitable targets for efficient immunotherapy strategies [74].

\subsection{Early Clinical Trials}

Early clinical trials on the E75 involved small number of patients with metastatic cancer and the vaccine was administered in combination with immunoadjuvant (incomplete Freund's adjuvant [IFA], GM-CSF), injected as a simple vaccine without a delivery system. The results demonstrated that the E75 peptide vaccine was safe and capable of inducing in vivo a peptide-specific immune response, however the clinical impact of such response on HER2 immunity was not observed [75] [76]. Currently, several other peptides are being used in clinical trials. They have been designed for HLA class-II presentation in combination with E75 or Nelipepimut-S, to elicit a predominant $\mathrm{CD}^{+} \mathrm{T}$-cell response that would strongly sustain immunological memory [71]-[73].

Nelipepimut-S has been used in multiple vaccine formulations; it has been loaded on to autologous dendritic cells, embedded in longer peptides capable of eliciting both CTL and CD4 ${ }^{+}$helper T-cell responses, and used as a single peptide combined with various immunoadjuvants [73] [74]. Unfortunately, when E75 was combined to generate multiple vaccines in a clinical trial setting only $26 \%$ of patients had $\mathrm{T}$ cell response after vaccination [77]. However, when E75 peptide was combined with other HER2 extracellular domain (ECD) or intracellular domain (ICD) derivatives of HLA class II peptides, 68\% of 64 women with breast cancer developed T cell response [78]. The T cell responses were $61 \%$ when E75 was combined with poly-lactide-co-glycolide (PLG) in 24 breast cancer patients [79]. A concurrent phase II trial that enrolled 186 patients-node-positive and nodenegative at high recurrence risk, reported that E75 mixed with GM-CSF resulted in a recurrence rate of 5.6\% in the vaccinated group versus $14.2 \%$ in the control group $(P=0.04)$ [80]. In another trial that enrolled 183 patients, a recurrence rate of $6.5 \%$ in all vaccinated patients was noted compared to $14.5 \%$ in the control group [81]. Despite the early positive results there are still major limitations in the efficacy of the E75 HER2 peptide vaccine discussed earlier. In addition, evidence has shown that the E75 immunity wanes over time as a result of a peculiar biology of MHC Class I short peptide vaccine stimulated $\mathrm{CDB}^{+} \mathrm{T}$ cells. These cells, in the absence of continued antigen exposure and stimulation by APCs are not capable of sustaining a prolonged memory immune response [82].

\subsection{HER2 GP2 (AA: 654-662) Peptide Vaccine}

The GP2 (AA 654-662: IISAVVGIL) is the second HER2-derived peptide of 9 amino acid, MHC class I peptide derived from the protein's transmembrane domain. Initial evaluation of GP2 suggested that compared with E75, it binded to human leukocyte antigen A2 (HLA-A2) with lower affinity and, therefore, was a subdominant HER2 epitope [76] [83]. However, a subsequent study confirmed the immunogenicity of the GP2 peptide; for example Mittendorf et al. [82] showed that GP2 peptide had immunogenicity comparable to that of E75, and 
suggested that the GP2 may be most beneficially used in a multiepitope vaccine. In vitro studies demonstrated that HLA-A2-positive breast cancer TIL lines recognize the GP2 peptide in cytotoxicity assays and that the GP2-sensitized CTLs acquired the ability to recognize HLA-A2-positive, HER2-expressing ovarian tumors. This indicates that GP2 is an immunogenic peptide and is recognized by the endogenous immune system [81]. Subsequently, other studies confirmed the application of GP2 in HER2-positive breast cancer treatment and for priming CTL. Studies demonstrated that DCs pulsed with GP2 primed CTL capable of lysing HLA-A2-positive, HER2-expressing cancer cells, suggesting that GP2 itself is a TAA found in epithelial malignancies [81]. A study that compared efficacy of HER2 GP2 vaccine to the use of immunotherapeutic adjuvant in inducing anti tumor immunity found that there were no grades 4 - 5 local toxicities and no grades 3-5 systemic toxicities [84] The author demonstrated that in vivo post-vaccination immune responses (measured by the delayed-type hypersensitivity (DTH)), were significantly stronger in the group that received GP2 + GM-CSF $(18.0 \pm 3.1 \mathrm{~cm})$ compared with the GM-CSF-only group $(0.5 \pm 3.3 \mathrm{~cm} ; P=0.002)$. Moreover, the percentage of GP2-specific CTLs was significantly increased from baseline, at 6 months after completion of the inoculation series in the GP2 + GM-CSF group $(0.65 \pm 0.15-1.82 \pm 0.23 ; P=0.002)$ compared with the GM-CSF-only group (1.08 $\pm 0.16-1.41 \pm 0.49 ; P=0.45)$ [84]. At a median follow-up of 17.9 months, a recurrence rate of $7.4 \%(2 / 27)$ was noted in the GP2 + GM-CSF group compared with $13 \%(3 / 23)$ in the GM-CSF-only group $(P=0.65)$. The author did not report data on disease free survival [84].

Furthermore, like in the E75 trials, early results from the GP2 + GM-CSF phase II trial suggest that adjuvant vaccine therapy may decrease the risk of recurrence in women with breast cancer who are disease-free but are at high risk for relapse. However, as previously alluded to, the single peptide vaccine strategy may not be optimal, as both the E75 and GP2 studies suggest that even though patients are able to expand the number of peptidespecific CTLs in response to vaccination, a large number of patients would fail to maintain high levels of immunity except when there is continued vaccination. This points to the need to design a vaccine that stimulates both the $\mathrm{CD}^{+}$and $\mathrm{CD}^{+} \mathrm{T}_{\mathrm{H}}$ cell responses simultaneously, such that while CTL stimulation acts as the main mediator of antitumor immunity, the addition of a $\mathrm{CD}^{+} \mathrm{T}_{\mathrm{H}}$ cell response may extend the duration of the CTL-mediated immunity, as well as promote the accumulation of APCs at the tumor site [85]-[87]. Nevertheless, early phase trials suggest that the GP2 peptide vaccine is safe; hence, it appears that this peptide may be an attractive candidate for broad application of immunotherapy and HER-2 cancer vaccines.

\subsection{HER2 Hybrid AE37 (AA: 776-790) Peptide Vaccine}

Given the limitations associated with the HER2 peptide vaccines discussed above including waning of immunity with progressive decrease in specific $\mathrm{CD} 8^{+} \mathrm{T}$ cells, there is a need for booster inoculations to sustain an effective peptide-specific immune response [88]. While the GP2 (GP2 + GM-CSF) vaccines stimulate CD8 ${ }^{+} \mathrm{T}$ cells which effectively elicit cytolytic activity directed against HER2-expressing tumors, concern exists that a durable vaccine-specific immune response may require the use of a $\mathrm{CD} 4^{+}$helper $\mathrm{T}$ cell epitope to establish a long-term memory CTL response. This has led to the strategy of immunization with a vaccine capable of primarily stimulating $\mathrm{CD}^{+}$helper $\mathrm{T}$ cells, such as the AE37 vaccine. The AE37 HER2 peptide vaccine is an MHC class II epitopes which is embedded to the MHC class me epitopes with the hope that vaccination will stimulate both $\mathrm{CD} 4^{+}$ and $\mathrm{CD}^{+} \mathrm{T}$ cell responses [88]. It is known that using longer peptides as MHC class II epitopes can function as a polyepitope vaccine with both $\mathrm{CD} 4^{+}$and $\mathrm{CD} 8^{+} \mathrm{T}$ cell epitopes present, this combination therefore could allow for more efficient immunization [88]. Consequently, a modification of the hybrid peptide vaccine has been reported [88] [89]. This involves amplifying the activity of MHC class II epitopes and linking it to a four-aminoacid moiety (LRMK; Ii-Key) to the N-terminal end of the epitope peptide either directly or by using a simple polyethylene spacer (-ava-) to produce the li-key HER2 peptide vaccine otherwise known as the AE37 [89]. IiKey is derived from the MHC class II-associated invariant chain (Ii protein). It catalyzes binding of the linked epitope to the MHC class II molecule, thereby enhances the overall potency of presentation. Several studies have demonstrated that Ii-Key/HER2 (776-790) hybrid (AE37) induces more potent immunologic responses, both in vitro and in vivo, compared with the non-modified HER2 $2_{776-790}$ peptide (AE36) [90]-[92]. Indeed, the Ii-Key hybrid AE37 has been shown to generate robust and long lasting HER2-specific immune responses in women with breast cancer. Preliminary data from a phase II study evaluated AE37 in women with breast cancer suggested a better outcome and indicated that the Ii-Key hybrid technology is capable of enhancing the potency of peptide immunotherapy for cancer [92]. 
The results of the first human phase I trial of the Ii-Key hybrid HER peptide (AE37) vaccine in women with early stage node-negative breast cancer demonstrated vaccine induced dose-dependent immunologic responses, in vitro and in vivo, to AE37 and AE36 (unmodified type), and showed that the hybrid AE37 vaccine was safe and well tolerated with minimal toxicity if properly dosed. AE37 is capable of eliciting HER2-specific immune responses; even without the use of an adjuvant [93]. This trial represents the first human experience with the Ii-Key modification. Due to the fact that no immunoadjuvants was added, the AE37 is the first peptide vaccine to show potency in the absence of an immunoadjuvant.

Furthermore, at the median follow up period of 22.3 months, $49 \%$ reduction in risk of breast cancer recurrence was noted in women treated with the AE37 peptide vaccine compared with the immunoadjuvant, GM-CSF alone. The risk reduction was higher (68\%) in women with low HER2 expressers (HER21 + or $2+$ on immunostaining) breast cancer [94], which is in line with the general concept that patients with biologically less aggressive disease may respond better to vaccination. Discussion on why HER2 negative patients had better outcome after vaccination is not within the scope of this work.

\subsection{Advantages and Disadvantages of HER2-Peptide Vaccines}

There are numerous advantages of vaccines that utilize immunogenic peptides. Peptide vaccines are chemically stable, do not include pathogens, are devoid of oncogenic potential, and are easy to construct, manufacture and administer. Peptide vaccines are also immunogenic, modifiable and combinable [94]. In addition, peptide vaccines have minimal systemic toxicity and offer the potential for prolonged immunity, which can be easily monitored. However, there are some disadvantages with HER2-peptide vaccines. These include the requirement of an adjuvant to elicit efficient CTL responses and HLA restriction (most of HER2-peptide vaccines are HLA-A2 restricted) and the lack of antigenic diversity especially with single-peptide vaccines [94].

\section{HER2-Specific Dendritic Cell Vaccine}

\subsection{Dendritic Cell Biology}

Mature dendritic cells (mDCs) are characterized by having numerous membrane processes that take the form of dendrites pseudopods or veils [95]. As the most potent antigen presenting cells (APCs) for the primary immune response, they are characterized by displaying high levels of major histocompatibility complex (MHC) class II antigen and various adhesion and costimulatory molecules (e.g. CD11a, CD11b, CD11c, CD54) on the surface [95] [96]. As with other APCs, the costimulation-associated molecules CD80, CD86, and CD40 are expressed on mature DCs and CD83 is now recognized as specific marker of matured human DCs [95] [96]. Whereas DCs can process Ags via the classical pathway, endogenous Ags are delivered via proteosomes into the MHC class I component, and exogenous Ags via endocytic lysosomes into the MHC class II compartment. DCs also pose an alternative pathway of Ag processing and can route exogenous Ags into the MHC class I pathway through a mechanism known as cross-priming. They can also utilize molecular chaperones, such as the heath shock protein (HSP), to deliver Ags via the MHC class I pathway [97]. Murine splenic DCs can express CD4 or CD8 markers. It is known that various subsets of DCs exist in humans and mice and that they play different roles in regulation of immune response [95] [96]. DCs migrate as precursors from bone marrow into various organs, where they usually reside in an immunologically inactive state, during which they possess the ability to efficiently endocytose and process antigens. Several stimuli can promote the maturation of iDCs (immature dendritic cells), these include but are not limited to microbe-associated molecular patterns (MAMPs), damage-associated molecular patterns (DAMPs), immune complexes as well as a wide panel of cytokines and chemokines [98].

As opposed to their immature counterparts, mDCs (mature dendritic cells) exhibit a limited ability to engulf Ags. However, they express elevated levels of MHC class II molecules on the cell surfaces; capable of migrating toward lymph nodes, owing to the expression of specific chemokine receptors (e.g., CCR7); and secrete high quantities of cytokines/chemokines [98]. Thus, mDCs are highly efficient in triggering adaptive immune responses, much more than other professional APCs including B cells and macrophages [95] [98]. Of note, the immunostimulatory potential of DCs is not restricted to the elicitation of cellular immune responses, but also impacts humoral immunity [96] [98].

Activated DCs undergo a differentiation process that down-regulate their Ag processing capabilities, but enhances the expression of MHC and costimulatory molecules which are important for successful antigen presentation [96]. They subsequently migrate to lymphoid organs to interact with naive T cells. The stimulated DCs 
ability to migrate into T cell-rich areas of lymph nodes is the key to successful induction of CTL immunity [96] [97]. Recent studies have demonstrated that chemokines play critical role in this directed migration. Imatured DCs respond to inflammatory chemokines (e.g., MCP-1, MIP-1 $\alpha$, MIP-3 $\alpha$, and RANTES) via their CCR1, CCR2, CCR5, CCR6, and CXCR1 receptors and are thereby drawn to the site of the inflammation, whereas matured DCs respond via the CCR-7 receptor to the MIP-3 $\beta$ and SLC that are expressed strongly in the lymph nodes [96].

\subsection{Loading of Antigens to Dendritic Cells}

Today a large array of cancer vaccination strategies based on DCs, are continuously emerging. Most of them are based on loading DCs with tumor-associated antigens, ex vivo or in vivo, in an attempt to utilize them as anticancer vaccines to elicit clinically relevant immune responses [99] [100]. This approach can be subdivided into three main classes. The first category involves ex vivo loading DCs (generated by culturing patient-derived hematopoietic progenitor cells or monocytes using specific cytokine combinations), with tumor-associated antigens (TAAs), in the presence of an adjuvant, to promote maturation of DCs, which is later re-infused into the patient with local doses of an adjuvant. Common method of the ex vivo loading of TAAs in DCs includes: (i) the co-incubation of DCs with whole tumor cell lysates or with apoptotic tumor cell corpses; (ii) the co-incubation of DCs with purified TAAs (encompassing both full-length proteins and short peptides); (iii) the transfection of DCs with tumor cell-derived mRNA; (iv) the genetic manipulation of DCs for the in vivo expression of TAAs; and (v) the fusion of DCs with tumor cells [101]. The second class involves an approach whereby TAAs are coupled onto a vector or antibodies before delivering them in vivo alongside DC maturation adjuvants (to prevent tolerance) to specifically recognize surface receptors [100]. The advantage of this approach is that it is of low cost and requires less time to perform, however, the mechanism by which immune responses develop using this approach is poorly understood. Full details of these methods have been extensively reviewed by Tyagi et al. [101] and Galluzzi et al. [100].

\subsection{HER2 Dendritic Cell Vaccine}

It is now established that DCs matured ex vivo in the presence of whole tumor cell lysates or apoptotic tumor cells, elicit therapeutic antitumor immunity in vivo. Currently, DCs are loaded with apoptotic tumor cells; pulsed with tumor cell lysates; fused with tumor cells or transfected with tumor-derived mRNA as a form of DC vaccine to elicit immune responses in vivo against cancers [102] [103]. Currently several phase I/II clinical trials are evaluating safety and efficacy of this therapeutic strategy in various malignancies. Early results are encouraging. It has been reported that DCs pulsed ex vivo with tumor cell lysates or with apoptotic cancer cells when administered to the patients lead to immune responses without major toxicity [102] [103]. DCs matured ex vivo in the presence of apoptotic tumor cells are being tested, as a single immunotherapeutic intervention in acute myeloid leukemia (AML) patients as well as in patients with brain neoplasm [102] [103], while DCs loaded ex vivo with tumor cell lysates are being evaluated in patients with B-cell lymphoma, brain cancer, neuroblastoma, sarcoma, breast cancer, or ovarian cancer [102] [103]. Among different methods, electroporation (EP) with apoptotic tumor cells into DCs is known to elicit more potent antigen-specific $\mathrm{CD} 8^{+} \mathrm{T}$ cells compared to co-incubation of tumor cell lysates with DCs in vitro.

Evidence has shown that DC-based vaccines are capable of causing expansion of circulating TAA-specific $\mathrm{CD}^{+}$and $\mathrm{CD}^{+}{ }^{+} \mathrm{T}$ cells. Most $\mathrm{T}$ cell responses are initiated in the paracortical region of the lymph nodes which contains Ag-bearing DCs. These cells migrate from inflamed tissues and activate antigen-specific $\mathrm{T}$ lymphocytes. Prior to vaccination or immunization, antigen-specific $\mathrm{CD}^{+} \mathrm{T}$ cells are present at a very low frequency (typically 1 in $10^{5}-10^{6} \mathrm{~T}$ cells) in the T cell repertoire; this allows antigen-bearing DCs to sample the available fraction of the $\mathrm{T}$ cell pool to physically engage one or several antigen-specific $\mathrm{T}$ cells, which upon the interaction would lead to $\mathrm{T}$ cell activation and clonal expansion. Naive $\mathrm{CD} 8^{+} \mathrm{T}$ cells initiate a CTL differentiation, and upon encountering DCs presenting a tumour-derived peptides, trigger a complex system of signals that result in $\mathrm{CD}^{+} \mathrm{T}$ cell expansion and differentiation; hence the quality of the $\mathrm{CD} 8^{+} \mathrm{T}$ cell differentiation is further regulated by $\mathrm{CD}^{+} \mathrm{T}$ cells which control the differentiation and expansion of tumour antigen-specific CTLs and induction of long-term memory CD8 ${ }^{+} \mathrm{T}$ cells [104] [105].

Surprisingly, $\mathrm{CD}^{+} \mathrm{T}$ cells have been shown to suppress CTL differentiation, for instance, regulatory $\mathrm{T}\left(\mathrm{T}_{\mathrm{Reg}}\right)$ cells can inhibit CTLs via IL-10, and compete with CD8 ${ }^{+} \mathrm{T}$ cells for IL-2 through constitutive expression of 
CD25 (also known as IL2R $\alpha$ ) [106]. In addition, $\mathrm{CD}^{+}$type-2 help $\mathrm{T}\left(\mathrm{T}_{\mathrm{H}} 2\right)$ cells inhibit the generation of CTLs by secreting IL-4, which on the other hand leads to generation of a subpopulation of CTLs, termed CD8 ${ }^{+}$type-2 cytotoxic $\mathrm{T}\left(\mathrm{T}_{\mathrm{c}} 2\right)$ cells, known to have limited killing capacity due to their low expression of granzymes and perforin [106]. Thus both $\mathrm{CD}^{+}$and $\mathrm{CD}^{+} \mathrm{T}$ cells have important role in modulation of post vaccination/immunization efficacy.

\subsection{HER2-Specific Dendritic Cell Vaccine; Experimental Evidence}

A preclinical study demonstrated that immunization with DCs transfected with an adenovirus encoding the HER2 protein delayed the onset of spontaneous HER2 over-expressing mammary tumors in BALB/c transgenic mice (which develop breast cancers as a consequence of mammary gland-specific expression of an activated neu oncogene) [107]. Specifically the study showed that vaccination of BALB-neuT mice with bone marrow-derived DCs transduced with Ad.Neu, a recombinant adenovirus expressing a truncated neu oncoprotein, stimulated the production of specific anti-neu antibodies, enhanced interferon-gamma expression by $\mathrm{T}$ cells, and prevented or delayed the onset of mammary carcinomas in the mice. It was shown that over $65 \%$ of vaccinated mice remained tumor free even at 28 weeks of age, whereas all mice in the control groups developed tumors [107]. When challenged with a neu-expressing breast cancer cell line, vaccinated tumor-free animals had delayed tumor growth compared with the controls. The antitumor effect of the vaccine was specific for expression of neu. The study demonstrated that $\mathrm{CD}^{4+} \mathrm{T}$ cells were required to generate antitumor immunity. DCs modified by recombinant adenoviruses expressing tumor-associated antigens may provide an effective antitumor vaccination strategy [107].

Another preclinical study tested the effectiveness of syngeneic DCs transfected with a construct in which HER2 ECD is fused with the transduction domain of the Tat protein [108]. It was shown that mice immunized intra-peritoneally (ip) with these DCs developed tumors of significantly smaller size than non-immunized animals or mice immunized with DCs transfected only with the Tat transduction domain [108]. Furthermore, an intraperitoneal injection of DCs vaccine resulted in migration of the DCs to secondary lymphoid organs, evidenced by small-animal positron emission tomography studies. The result revealed that the immunized mice developed palpable tumors significantly later than the control mice who were injected with DC-Tat-empty $(P=$ 0.001 and $P<0.05$ for two immunizations and for one immunization, respectively) [108]. Similarly, immunized mice had smaller tumors than mice injected with DC-Tat-empty $(P<0.05$ and $P<0.01)$ or untreated mice $(P<0.001$ and $P<0.001)$. Of note, significantly more tumor-specific CD8(+) splenocytes were found in twice-immunized mice than in untreated animals [108].

Chen et al. [109] and Tatsumi et al. [110] have independently shown that when an adenovirus was constructed to express both HER2 and IL-12 to serve as an adjuvant, and was transfected the bone marrow derived DCs, the resultant HER2 DC vaccine induced tumor protection in FVB mice challenged with syngeneic HER2 over-expressing tumor cells. They also demonstrated that both $\mathrm{CD}^{+}{ }^{+}$and $\mathrm{CD}^{+} \mathrm{T}$ cells were necessary to elicit the immune response. In fact, a subcutaneous (s.c.) immunization with the DC vaccine resulted in protective immunity in approximately $60 \%$ of the animals. The CTL analysis demonstrated specific cytotoxic activity against breast tumor cells [109] [110]. Their research provides the evidence that in a therapeutic setting, immunization with the DC vaccines could cure mice with pre-established tumors, hence the efficacy of such vaccine could be further enhanced by co-transducing DCs with a vector expressing murine IL-12 [109] [110].

Furthermore, an enhanced HER2-specific antitumor immunity was reported by transducing mouse DCs with two genes encoding HER2 and alpha tumor necrosis factor (TNF- $\alpha$ ) [111] [112]. The researchers demonstrated that this approach resulted in the secretion of a significant amount of TNF- $\alpha(8 \mathrm{ng} / \mathrm{mL})$ and an up-regulation of co-stimulatory molecules like CD40, CD86 and ICAM-I [111]. In line with the evidence from previous reports, that study clearly indicated that vaccination with $\mathrm{DC}_{\mathrm{HER} 2}$ protected $25 \%$ of the mice from tumor growth after challenge with aggressive breast cancer phenotype (MCA26 $6_{\mathrm{HER} 2}$ ) whereas vaccination with $\mathrm{DC}_{\mathrm{HER} 2 / \mathrm{TNF}-\alpha}$ provided 100\% HER2-positive antitumor immunity; suggesting that vaccination with $\mathrm{DC}_{\mathrm{HER} 2 / \mathrm{TNF}-\alpha}$ is likely to induce stronger allogeneic T-cell proliferation and HER2-specific CTL responses [111].

In a related study, Chan et al. [112] used in vivo murine tumor model expressing rat neu Ag to compare the efficacy between recombinant adenovirus (AdVneu)-transfected DCs (DCneu) and DNA base vaccine (plasmid DNA (pcDNAneu)), and showed that vaccination with DCneu induced stronger HER2/neu-specific humoral and cellular CTL immune responses than DNA vaccination, which downregulated HER2/neu expression and lysed HER2/neu-positive tumor cells in vitro, respectively [112]. In a separate experiment, the author also demon- 
strated that DCneu vaccine completely protected mice from tumor cell challenge compared to a partial or no protection found with DNA-immunized mice. They showed that DCneu significantly delay breast cancer development in transgenic mice compared with DNA vaccine $(P<0.05)$, suggesting that HER2/neu-gene-modified DC vaccine is more potent than DNA vaccine in animal tumor models.

Sas et al. [113] used RGD-modified AdVneu, a recombinant adenovirus that encodes the rat neu protein and the arg-gly-asp (RGD) motif. The addition of the RGD motif in the construct was reported to efficiently increase expression of neu. The authors transfected DCs with RGD-modified AdVneu (DCneu2 cells) or AdVneu alone (DCneu1 cells) and evaluated the anti-HER2/neu cellular and humoral responses and antitumor immunity from

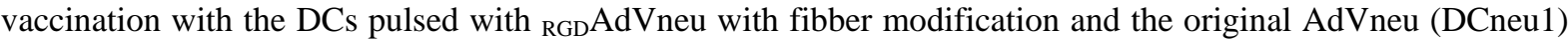
without fibber modification in wild-type FVB/NJ and transgenic (Tg) FVBneuN mice with self-neu immune tolerance (DCneu2) [113]. The authors found that DCneu2 displayed increased neu expression by 8.3-fold compared to DCneu1, and that DCneu2 vaccination induced stronger neu-specific humoral and CTL immune responses than DCneu1 vaccination, hence, DCneu2 vaccination protected all the mice from neu-expressing Tg1-1 breast cancer cell challenge in wild-type FVB/NJ mice, compared to only a partial protection in DCneu1-immunized mice [113]. The study further showed significant delay of tumor growth in the DCneu2 vaccinated mice than DCneu1 immunization $(P<0.05)$ in transgenic $(\mathrm{Tg})$ FVBneuN mice with neu-specific self-immune tolerance.

\subsection{HER2-Specific Dendritic Vaccine; Clinical Evidence}

Three clinical trials are currently in progress using loaded-DCs. A study involving 6 patients with breast or ovarian cancer who were immunized subcutaneously with DCs loaded with two peptides derived from HER2: p369 (amino acids aa 369 - 377) and p654 (aa 654 - 662) [114]. It was reported that patients with advanced breast and ovarian cancer can be efficiently vaccinated with autologous DCs pulsed with HER2- or MUC1-derived peptides [114]. In 5 of 10 patients, DC vaccination resulted in HER2-specific CTLs which was detectable in the peripheral blood using both intracellular IFN-gamma staining and (51)Cr-release assays [114].

Morse et al. conducted a pilot study in seven women with high-risk stage II, III or resected stage IV HER2positive breast cancer, which were disease free after surgery and adjuvant therapy [115]. Vaccine was comprised of both mature and immature autologous DC loaded with HER2 intracellular domain (ICD) peptide. Patients continued adjuvant hormonal therapy after immunization. No relevant toxic effects were reported. Six patients developed immunological T cell response against HER2 ICD and specific antibodies. Specifically, delayed-type hypersensitivity (DTH) reactions at the injection site occurred in 6 of 7 patients and HER2 specificity was detected by cytokine flow cytometry or ELISPOT in 5 patients. After a follow up period of more than 5 years, 6 of 7 women had detectable anti-ICD antibodies [115]. One patient experienced a pulmonary recurrence at 4 years that was resected. All patients were alive and disease free at 5-year follow up. The report suggests that vaccination with HER2 ICD protein-containing DC is an appropriate therapeutic option for evaluation

Peethambaram et al. [116] reported results of a phase I clinical trial with lapuleucel-T (APC8024). Lapuleucel-T consists of autologous APCs loaded with a recombinant antigen including the extensive HER2 sequence linked to GM-CSF domain. Eighteen patients with metastatic breast, ovarian, and colorectal cancer were treated. The patients showed an immune response to the immunizing antigen (BA7072) at week 8 compared with week 0 as measured by T lymphocyte proliferation and IFN- $\gamma$ enzyme-linked immunospot assay. Therapy was well tolerated. The majority (94.7\%) of adverse events associated with treatment were mild to moderate (grade 1 or 2). Two patients experienced stable disease lasting more than 48 weeks. The report suggests that lapuleucel-T stimulated an immune response specific to the immunizing antigen and was well tolerated. Another phase II study on HER2 ICD-vaccine combined with trastuzumab in women with HER2-positive metastatic breast cancer reported that vaccine was well tolerated without unexpected adverse events and that majority of patients (75\%) developed robust $\mathrm{CD}^{+}$and $\mathrm{CD} 4^{+} \mathrm{T}$-cell responses, indicating that combinations of HER2 vaccines with other anti-HER2 therapies is feasible [117].

HER2 specific DC vaccine has also been evaluated in women with non-invasive breast cancer. A study that involved 13 patients with HER2-positive ductal carcinoma in situ (DCIS) who received 4 weekly vaccinations of DCs-pulsed with HER2 HLA class I and II peptides before surgery, showed high rates of HER2 peptide-specific sensitization for both IFN-gamma-secreting $\mathrm{CD}^{+}(85 \%)$ and $\mathrm{CD} 8^{+}(80 \%)$ T cells with recognition of antigenically relevant breast cancer lines, accumulation of $\mathrm{T}$ and $\mathrm{B}$ cells in the breast, and induction of complement-dependent, tumor-lytic antibodies (Abs) after vaccination [118]. Notably, three (11\%) patients devel- 
oped transient asymptomatic decrements in cardiac ejection fraction $>15 \%$ after vaccination; this was the first report of association with cardiac dysfunction with HER2 vaccination. In addition, 7 of 11 patients showed markedly decreased HER2 expression, in surgical tumor specimen, often with measurable decreases in residual DCIS, suggesting an active process of "immunoediting" of HER2-expressing tumor cells following vaccination [118] and potential role of the vaccine in primary prevention.

Finally, after it was discovered that in the presence of appropriate stimulatory signals, DCs can elicit robust (and hence potentially therapeutic) antitumor immune responses; multiple strategies have been devised to harness the immune systems for cancer therapy. The efficacy of these approaches has been promptly demonstrated in murine tumor models, encouraging the launch of several Phases I/II clinical trials. In the vast majority of these studies, the administration of DCs was found to be safe and at least in a fraction of patients stimulated detectable antitumor responses. Clinical benefits ranging from disease stabilization to complete responses have also been observed in a variable number of cases Although few clinical studies have been are performed, from the available evidences it appears that HER2 DC vaccination strategies may have potential for both prevention and treatment of early breast cancer

\section{Combining Active HER2 Vaccination with Adoptive Trastuzumab Therapy}

It has been demonstrated that combinatorial approaches of active HER2 vaccination with adoptive trastuzumab antibody therapy are likely to increase the effectiveness of each approach alone. Norell et al. conducted a pilot trial study involving 8 patients with metastatic HER2-positive breast cancer using HER2-DNA vaccine in combination with IL-2, GM-CSF and the humanized antibody trastuzumab therapy [46]. Treatment induced immediate and strong antibody and CTL responses. Notably, two of six patients, who completed all three vaccine cycles, were long-term survivors and are still alive more than 4 years after the last vaccination. Disis et al. reported a phase I/II trial study on 22 pretreated patients with HER2-positive stage IV breast cancer using trastuzumab combined with HER2-peptide vaccine [119]. The combination approach did not result in additional toxic side effects. After a median follow-up of 36 months, the median progression free survival (PFS) was 17.7 months, and estimated PFS at 3 years was 33\% [119]. Benavides et al. conducted a trial study using trastuzumab combined with E75 peptide vaccine [120]. There were four recurrences and one death among vaccine-alone patients $(n=27)$, but no recurrence or death in the group treated with combination therapy $(n=7)$ [120]. Other studies using trastuzumab in combination with HER2-protein vaccination have demonstrated favorable findings for the combinational approaches [117] [121]. These data indicate that combinatorial approaches of HER2 vaccines with adoptive trastuzumab immunotherapy are likely to increase the effectiveness of each approach alone.

\section{Conclusions and Perspectives}

Cancer vaccines target only tumor cells while preserving normal tissues from a non-specific toxicity. Notwithstanding the fact that HER2/neu cancer vaccines are safe and highly tolerable, currently there is very limited evidence of their benefit in the clinical settings. The limited benefit can be explained by (i) harmful effect of chemotherapy and radiation on the immune system prior to vaccination; (ii) the difficulty to break the immune tolerance against the HER2 antigen; (iii) the ability of cancer cells to escape the immune system; and (iv) the patients population (different stages of the disease and many with too advanced or refractory disease chosen for immunization). One of the major challenges with HER2 cancer vaccine is the complex immuno-escaping mechanisms often developed by the cancer cells. Although the regulatory cells like Tregs and molecular immunecheckpoints (e.g. CTLA-4, PD1/PD1L) play crucial roles in maintaining self-tolerance, cancer cells are able to exploit these elements to survive immune response following immunotherapy. New strategies based on blocking antibodies and recombinant forms of ligands or receptor to block the modulatory checkpoints thereby to enhance the immune response are required for effective cancer immunotherapy. Furthermore, research on newer type of HER2 cancer vaccines, more potent immune-adjuvant, best route of administration, and better patient selection could overcome some limitations currently faced by various anti-HER2 vaccine strategies and approaches.

In summary, targeting HER2-positive breast cancer using vaccination or active immunization appears feasible. To date, different forms of HER2 cancer vaccine are continuously evolving with early positive results. The current limitations provide opportunities to improve efficacy of HER2 cancer vaccines. A better understanding of the complexity of tumor biology and immunology, discovery of new novel immunotherapeutics and establishment of new combinatorial treatment protocols will eventually help in developing efficient HER2-specific im- 
munotherapy for HER2-positive breast cancer patients.

\section{References}

[1] Wieduwilt, M.J. and Moasser, M.M. (2008) The Epidermal Growth Factor Receptor Family: Biology Driving Targeted Therapeutics. Cellular and Molecular Life Sciences, 65, 1566-1584. http://dx.doi.org/10.1007/s00018-008-7440-8

[2] Hynes, N.E. and MacDonald, G. (2009) ErbB Receptors and Signaling Pathways in Cancer. Current Opinion in Cell Biology, 21, 177-184. http://dx.doi.org/10.1016/j.ceb.2008.12.010

[3] Milani, A., Sangiolo, D., Montemurro, F., Aglietta, M. and Valabrega, G. (2013) Active Immunotherapy in HER2 Overexpressing Breast Cancer: Current Status and Future Perspectives. Annals of Oncology, 24, 1740-1748. http://dx.doi.org/10.1093/annonc/mdt133

[4] Tebbutt, N., Pedersen, M.W. and Johns, T.G. (2013) Targeting the ERBB Family in Cancer: Couples Therapy. Nature Reviews Cancer, 13, 663-673. http://dx.doi.org/10.1038/nrc3559

[5] Yarden, Y. and Pines, G. (2012) The ERBB Network: At Last, Cancer Therapy Meets Systems Biology. Nature Reviews Cancer, 12, 553-563. http://dx.doi.org/10.1038/nrc3309

[6] Kirouac, D.C., Du, J.Y., Lahdenranta, J., Overland, R., Yarar, D., Paragas, V., Pace E., McDonagh, C.F., Nielsen, U.B. and Onsum, M.D. (2013) Computational Modeling of ERBB2-Amplified Breast Cancer Identifies Combined ErbB2/3 Blockade as Superior to the Combination of MEK and AKT Inhibitors. Science Signaling, 6, ra68. http://dx.doi.org/10.1126/scisignal.2004008

[7] Hynes, N.E. and Lane, H.A. (2005) ERBB Receptors and Cancer: The Complexity of Targeted Inhibitors. Nature Reviews Cancer, 5, 341-354. http://dx.doi.org/10.1038/nrc1609

[8] Bailey, T.A., Luan, H., Clubb, R.J., Naramura, M., Band, V., Raja, S.M. and Band, H. (2011) Mechanisms of Trastuzumab Resistance in ErbB2-Driven Breast Cancer and Newer Opportunities to Overcome Therapy Resistance. Journal of Carcinogenesis, 10, 28. http://dx.doi.org/10.4103/1477-3163.90442

[9] Jackson, C., Browell, D., Gautrey, H. and Tyson-Capper, A. (2013) Clinical Significance of HER-2 Splice Variants in Breast Cancer Progression and Drug Resistance. International Journal of Cell Biology, 2013, Article ID: 973584. http://dx.doi.org/10.1155/2013/973584

[10] Hart, M.R., Su, H.Y., Broka, D., Goverdhan, A. and Schroeder, J.A. (2013) Inactive ERBB Receptors Cooperate with Reactive Oxygen Species to Suppress Cancer Progression. Molecular Therapy, 21, 1996-2007. http://dx.doi.org/10.1038/mt.2013.196

[11] Yarden, Y. and Sliwkowski, M.X. (2001) Untangling the ErbB Signalling Network. Nature Reviews Molecular Cell Biology, 2, 127-137. http://dx.doi.org/10.1038/35052073

[12] Montemurro, F. and Scaltriti, M. (2014) Biomarkers of Drugs Targeting HER-Family Signalling in Cancer. Journal of Pathology, 232, 219-229. http://dx.doi.org/10.1002/path.4269

[13] Schechter, A.L., Hung, M.C., Vaidyanathan, L., Weinberg, R.A., Yang-Feng, T.L., Francke, U., Ullrich, A. and Coussens, L. (1985) The Neu Gene: An ErbB-Homologous Gene Distinct from and Unlinked to the Gene Encoding the EGF Receptor. Science, 229, 976-978. http://dx.doi.org/10.1126/science.2992090

[14] Dendukuri, N., Khetani, K., McIsaac, M. and Brophy, J. (2007) Testing for HER2-Positive Breast Cancer: A Systematic Review and Cost-Effectiveness Analysis. Canadian Medical Association Journal, 176, 1429-1434. http://dx.doi.org/10.1503/cmaj.061011

[15] Ross, J.S., Slodkowska, E.A., Symmans, W.F., Pusztai, L., Ravdin, P.M. and Hortobagyi, G.N. (2009) The HER-2 Receptor and Breast Cancer: Ten Years of Targeted Anti-HER-2 Therapy and Personalized Medicine. Oncologist, 14, 320-368. http://dx.doi.org/10.1634/theoncologist.2008-0230

[16] Dawood, S., Broglio, K., Buzdar, A.U., Hortobagyi, G.N. and Giordano, S.H. (2010) Prognosis of Women with Metastatic Breast Cancer by HER2 Status and Trastuzumab Treatment: An Institutional-Based Review. Journal of Clinical Oncology, 28, 92-98. http://dx.doi.org/10.1200/JCO.2008.19.9844

[17] Olson, E.M. (2012) Maximizing Human Epidermal Growth Factor Receptor 2 Inhibition: A New Oncologic Paradigm in the Era of Targeted Therapy. Journal of Clinical Oncology, 30, 1712-1714. http://dx.doi.org/10.1200/JCO.2011.40.2545

[18] Slamon, D.J., Clark, G.M., Wong, S.G., Levin, W.J., Ullrich, A. and McGuire, W.L. (1987) Human Breast Cancer: Correlation of Relapse and Survival with Amplification of the HER-2/Neu Oncogene. Science, 235, 177-182. http://dx.doi.org/10.1126/science.3798106

[19] Kumar, G. and Badve, S. (2008) Milestones in the Discovery of HER2 Proto-Oncogene and Trastuzumab (Herceptin). Connection, 13, 9-14.

[20] Carter, P., Presta, L., Gorman, C.M., Ridgway, J.B., Henner, D., Wong, W.L., Rowland, A.M., Kotts, C., Carver, M.E. 
and Shepard, H.M. (1992) Humanization of an Anti-p185HER2 Antibody for Human Cancer Therapy. Proceedings of the National Academy of Sciences of the United States of America, 89, 4285-4289. http://dx.doi.org/10.1073/pnas.89.10.4285

[21] Hudis, C.A. (2007) Trastuzumab-Mechanism of Action and Use in Clinical Practice. New England Journal of Medicine, 357, 39-51. http://dx.doi.org/10.1056/NEJMra043186

[22] Lollini, P.L. and Forni, G. (2003) Cancer Immunoprevention: Tracking Down Persistent Tumor Antigens. Trends in Immunology, 24, 62-66. http://dx.doi.org/10.1016/S1471-4906(02)00030-3

[23] Finn, O.J. (2003) Cancer Vaccines: Between the Idea and the Reality. Nature Reviews Immunology, 3, 630-641. http://dx.doi.org/10.1038/nri1150

[24] Lollini, P.L., Cavallo, F., Nanni, P. and Forni, G. (2006) Vaccines for Tumour Prevention. Nature Reviews Cancer, 6, 204-216. http://dx.doi.org/10.1038/nrc1815

[25] Cavallo, F.D., Giovanni, C., Nanni, P., Forni, G. and Lollini, P.L. (2011) 2011: The Immune Hallmarks of Cancer. Cancer Immunology, Immunotherapy, 60, 319-326. http://dx.doi.org/10.1007/s00262-010-0968-0

[26] Whittington, P.J., Radkevich, B.O., Jacob, J.B., Jones, R.F., Weise, A.M. and Wei, W.Z. (2009) Her-2 DNA versus Cell Vaccine: Immunogenicity and Anti-Tumor Activity. Cancer Immunology, Immunotherapy, 58, 759-767. http://dx.doi.org/10.1007/s00262-008-0599-x

[27] Bodles-Brakhop, A.M., Heller, R. and Draghia-Akli, R. (2009) Electroporation for the Delivery of DNA-Based Vaccines and Immunotherapeutics: Current Clinical Developments. Molecular Therapy, 17, 585-592. http://dx.doi.org/10.1038/mt.2009.5

[28] Liu, M.A. (2003) DNA Vaccines: A Review. Journal of Internal Medicine, 253, 402-410. http://dx.doi.org/10.1046/j.1365-2796.2003.01140.x

[29] Radkevich-Brown, O., Jacob, J., Kershaw, M. and Wei, W.Z. (2009) Genetic Regulation of the Response to Her-2 DNA Vaccination in Human Her-2 Transgenic Mice. Cancer Research, 69, 212-218. http://dx.doi.org/10.1158/0008-5472.CAN-08-3092

[30] Nguyen-Hoai, T., Kobelt, D., Hohn, O., Vu, M.D., Schlag, P.M., Dörken, B., Norley, S., Lipp, M., Walther, W., Pezzutto, A. and Westermann, J. (2012) HER2/Neu DNA Vaccination by Intradermal Gene Delivery in a Mouse Tumor Model: Gene Gun Is Superior to Jet Injector in Inducing CTL Responses and Protective Immunity. OncoImmunology, 1, 1537-1545. http://dx.doi.org/10.4161/onci.22563

[31] Wei, W.Z., Shi, W.P., Galy, A., Lichlyter, D., Hernandez, S., Groner, B., Heilbrun, L. and Jones, R.F. (1999) Protection against Mammary Tumor Growth by Vaccination with Full-Length, Modified Human ErbB-2 DNA. International Journal of Cancer, 81, 748-754. http://dx.doi.org/10.1002/(SICI)1097-0215(19990531)81:5<748::AID-IJC14>3.0.CO;2-6

[32] Pilon, S.A., Piechocki, M.P. and Wei, W.Z. (2001) Vaccination with Cytoplasmic ErbB-2 DNA Protects Mice from Mammary Tumor Growth without Anti-ErbB-2 Antibody. Journal of Immunology, 167, 3201-3206. http://dx.doi.org/10.4049/jimmunol.167.6.3201

[33] Pupa, S.M., Iezzi, M., Di, C.E., Invernizzi, A., Cavallo, F., Meazza, R., Comes, A., Ferrini, S., Musiani, P. and Ménard, S. (2005) Inhibition of Mammary Carcinoma Development in HER-2/Neu Transgenic Mice through Induction of Autoimmunity by Xenogeneic DNA Vaccination. Cancer Research, 65, 1071-1078.

[34] Jacob, J.B., Kong, Y.C., Nalbantoglu, I., Snower, D.P. and Wei, W.Z. (2009) Tumor Regression Following DNA Vaccination and Regulatory T Cell Depletion in Neu Transgenic Mice Leads to an Increased Risk for Autoimmunity. Journal of Immunology, 182, 5873-5881. http://dx.doi.org/10.4049/jimmunol.0804074

[35] Fioretti, D., Iurescia, S., Fazio, V.M. and Rinaldi, M. (2010) DNA Vaccines: Developing New Strategies against Cancer. Journal of Biomedicine and Biotechnology, 2010, Article ID: 174378. http://dx.doi.org/10.1155/2010/174378

[36] Chen, Y., Hu, D., Eling, D.J., Robbins, J. and Kipps, T.J. (1998) DNA Vaccines Encoding Full-Length or Truncated Neu Induce Protective Immunity against Neu-Expressing Mammary Tumors. Cancer Research, 58, 1965-1971.

[37] Cao, J., Jin, Y., Li, W., Zhang, B., He, Y., Liu, H., Xia, N., Wei, H. and Yan, J. (2013) DNA Vaccines Targeting the Encoded Antigens to Dendritic Cells Induce Potent Antitumor Immunity in Mice. BMC Immunology, $14,39$. http://dx.doi.org/10.1186/1471-2172-14-39

[38] Jacob, J.B., Quaglino, E., Radkevich-Brown, O., Jones, R.F., Piechocki, M.P., Reyes, J.D., et al. (2010) Combining Human and Rat Sequences in HER-2 DNA Vaccines Blunts Immune Tolerance and Drives Antitumor Immunity. Cancer Research, 70, 119-128. http://dx.doi.org/10.1158/0008-5472.CAN-09-2554

[39] Occhipinti, S., Sponton, L., Rolla, S., Caorsi, C., Novarino, A., Donadio, M., Bustreo, S., Satolli, M.A., Pecchioni, C., Marchini, C., Amici, A., Cavallo, F., Cappello, P., Pierobon, D., Novelli, F. and Giovarelli, M. (2014) Chimeric Rat/Human HER2 Efficiently Circumvents HER2 Tolerance in Cancer Patients. Clinical Cancer Research, 20, 29102921. http://dx.doi.org/10.1158/1078-0432.CCR-13-2663 
[40] Collison, L.W., Workman, C.J., Kuo, T.T., Boyd, K., Wang, Y., Vignali, K.M., Cross, R., Sehy, D., Blumberg, R.S. and Vignali, D.A. (2007) The Inhibitory Cytokine IL-35 Contributes to Regulatory T-Cell Function. Nature, 450, 566569. http://dx.doi.org/10.1038/nature06306

[41] Wei, H., Wang, S., Zhang, D., Hou, S., Qian, W., Li, B., Guo, H., Kou, G., He, J., Wang, H. and Guo, Y. (2009) Targeted Delivery of Tumor Antigens to Activated Dendritic Cells via CD11c Molecules Induces Potent Antitumor Immunity in Mice. Clinical Cancer Research, 15, 4612-4621. http://dx.doi.org/10.1158/1078-0432.CCR-08-3321

[42] Wei, W.Z., Jacob, J.B., Zielinski, J.F., Flynn, J.C., Shim, K.D., Alsharabi, G., Giraldo, A.A. and Kong, Y.C. (2005) Concurrent Induction of Antitumor Immunity and Autoimmune Thyroiditis in CD4 ${ }^{+} \mathrm{CD} 25^{+}$Regulatory T Cell-Depleted Mice. Cancer Research, 65, 8471-8478. http://dx.doi.org/10.1158/0008-5472.CAN-05-0934

[43] de León, J., Fernández, A., Clavell, M., Labrada, M., Bebelagua, Y., Mesa, C. and Fernández, L.E. (2008) Differential Influence of the Tumour-Specific Non-Human Sialic Acid Containing GM3 Ganglioside on CD4 ${ }^{+}$CD25 $5^{-}$Effector and Naturally Occurring CD4 ${ }^{+} \mathrm{CD}_{2} 5^{+}$Regulatory T Cells Function. International Immunology, 20, 591-600. http://dx.doi.org/10.1093/intimm/dxn018

[44] Rolla, S., Ria, F., Occhipinti, S., Di Sante, G., Iezzi, M., Spadaro, M., Nicolò, C., Ambrosino, E., Merighi, I.F., Musiani, P., Forni, G. and Cavallo, F. (2010) Erbb2 DNA Vaccine Combined with Regulatory T Cell Deletion Enhances Antibody Response and Reveals Latent Low-Avidity T Cells: Potential and Limits of Its Therapeutic Efficacy. Journal of Immunology, 184, 6124-6132. http://dx.doi.org/10.4049/jimmunol.0901215

[45] Emens, L.A., Asquith, J.M., Leatherman, J.M., Kobrin, B.J., Petrik, S., Laiko, M., Levi, J., Daphtary, M.M., Biedrzycki, B., Wolff, A.C., Stearns, V., Disis, M.L., Ye, X., Piantadosi, S., Fetting, J.H., Davidson, N.E. and Jaffee, E.M. (2009) Timed Sequential Treatment with Cyclophosphamide, Doxorubicin, and an Allogeneic Granulocyte-Macrophage Colony-Stimulating Factor-Secreting Breast Tumor Vaccine: A Chemotherapy Dose-Ranging Factorial Study of Safety and Immune Activation. Journal of Clinical Oncology, 27, 5911-5918. http://dx.doi.org/10.1200/JCO.2009.23.3494

[46] Norell, H., Poschke, I., Charo, J., Wei, W.Z., Erskine, C., Piechocki, M.P., Knutson, K.L., Bergh, J., Lidbrink, E. and Kiessling, R. (2010) Vaccination with a Plasmid DNA Encoding HER-2/Neu Together with Low Doses of GM-CSF and IL-2 in Patients with Metastatic Breast Carcinoma: A Pilot Clinical Trial. Journal of Translational Medicine, 8, 53. http://dx.doi.org/10.1186/1479-5876-8-53

[47] Ladjemi, M.Z., Jacot, W., Chardès, T., Pèlegrin, A. and Navarro-Teulon, I. (2010) Anti-HER2 Vaccines: New Prospects for Breast Cancer Therapy. Cancer Immunology, Immunotherapy, 59, 1295-1312. http://dx.doi.org/10.1007/s00262-010-0869-2

[48] Diaz, C.M., Chiappori, A., Aurisicchio, L., Bagchi, A., Clark, J., Dubey, S., Fridman, A., Fabregas, J.C., Marshall, J., Scarselli, E., La Monica, N., Ciliberto, G. and Montero, A.J. (2013) Phase I Studies of the Safety and Immunogenicity of Electroporated HER2/CEA DNA Vaccine Followed by Adenoviral Boost Immunization in Patients with Solid Tumors. Journal of Translational Medicine, 11, 62.

[49] Provinciali, M., Smorlesi, A., Donnini, A., Bartozzi, B. and Amici, A. (2003) Low Effectiveness of DNA Vaccination against HER-2/Neu in Ageing. Vaccine, 21, 843-848. http://dx.doi.org/10.1016/S0264-410X(02)00530-3

[50] Provinciali, M., Barucca, A., Pierpaoli, E., Orlando, F., Pierpaoli, S. and Smorlesi, A. (2012) In Vivo Electroporation Restores the Low Effectiveness of DNA Vaccination against HER-2/Neu in Aging. Cancer Immunology, Immunotherapy, 61, 363-371. http://dx.doi.org/10.1007/s00262-011-1107-2

[51] Quaglino, E., Iezzi, M., Mastini, C., Amici, A., Pericle, F., Di Carlo, E., Pupa, S.M., De Giovanni, C., Spadaro, M., Curcio, C., Lollini, P.L., Musiani, P., Forni, G. and Cavallo, F. (2004) Electroporated DNA Vaccine Clears Away Multifocal Mammary Carcinomas in Her-2/Neu Transgenic Mice. Cancer Research, 64, 2858-2864. http://dx.doi.org/10.1158/0008-5472.CAN-03-2962

[52] Aichele, P., Hengartner, H., Zinkernagel, R.M. and Schulz, M. (1990) Antiviral Cytotoxic T Cell Response Induced by in Vivo Priming with a Free Synthetic Peptide. Journal of Experimental Medicine, 171, 1815-1820. http://dx.doi.org/10.1084/jem.171.5.1815

[53] Ossevoort, M.A., Feltkamp, M.C., Veen, K.J., Melief, C.J. and Kast, W.M. (1995) Dendritic Cells as Carriers for a Cytotoxic T-Lymphocyte Epitope-Based Peptide Vaccine in Protection against a Human Papillomavirus Type 16-Induced Tumor. Journal of Immunotherapy with Emphasis on Tumor Immunology, 18, 86-94. http://dx.doi.org/10.1097/00002371-199508000-00002

[54] Melief, C.J. and Burg, S.H. (2008) Immunotherapy of Established (Pre)malignant Disease by Synthetic Long Peptide Vaccines. Nature Reviews Cancer, 8, 351-360. http://dx.doi.org/10.1038/nrc2373

[55] Rosenberg, S.A., Yang, J.C. and Restifo, N.P. (2004) Cancer Immunotherapy: Moving beyond Current Vaccines. Nature Medicine, 10, 909-915. http://dx.doi.org/10.1038/nm1100

[56] Bijker, M.S., Eeden, S.J., Franken, K.L., Melief, C.J., Offringa, R. and Burg, S.H. (2007) CD8 ${ }^{+}$CTL Priming by Exact Peptide Epitopes in Incomplete Freund's Adjuvant Induces a Vanishing CTL Response, Whereas Long Peptides Induce Sustained CTL Reactivity. Journal of Immunology, 179, 5033-5040. http://dx.doi.org/10.4049/jimmunol.179.8.5033 
[57] Schulz, M., Zinkernagel, R.M. and Hengartner, H. (1991) Peptide-Induced Antiviral Protection by Cytotoxic T Cells. Proceedings of the National Academy of Sciences of the United States of America, 88, 991-993. http://dx.doi.org/10.1073/pnas.88.3.991

[58] Fayolle, C., Deriaud, E. and Leclerc, C. (1991) In Vivo Induction of Cytotoxic T Cell Response by a Free Synthetic Peptide Requires CD4 ${ }^{+}$T Cell Help. Journal of Immunology, 147, 4069-4073.

[59] Schuurhuis, D.H., Laban, S., Toes, R.E., Ricciardi-Castagnoli, P., Kleijmeer, M.J., Voort, E.I., Rea, D., Offringa, R., Geuze, H.J., Melief, C.J. and Ossendorp, F. (2000) Immature Dendritic Cells Acquire CD8 ${ }^{+}$Cytotoxic T Lymphocyte Priming Capacity upon Activation by T Helper Cell-Independent or -Dependent Stimuli. Journal of Experimental Medicine, 192, 145-150. http://dx.doi.org/10.1084/jem.192.1.145

[60] Scheibenbogen, C., Schadendorf, D., Bechrakis, N.E., Nagorsen, D., Hofmann, U., Servetopoulou, F., Letsch, A., Philipp, A., Foerster, M.H., Schmittel, A., Thiel, E. and Keilholz, U. (2003) Effects of Granulocyte-Macrophage Colony-Stimulating Factor and Foreign Helper Protein as Immunologic Adjuvants on the T-Cell Response to Vaccination with Tyrosinase Peptides. International Journal of Cancer, 104, 188-194. http://dx.doi.org/10.1002/ijc.10961

[61] Block, M.S., Suman, V.J., Nevala, W.K., Kottschade, L.A., Creagan, E.T., Kaur, J.S., Quevedo, J.F., McWilliams, R.R. and Markovic, S.N. (2011) Pilot Study of Granulocyte-Macrophage Colony-Stimulating Factor and Interleukin-2 as Immune Adjuvants for a Melanoma Peptide Vaccine. Melanoma Research, 21, 438-445. http://dx.doi.org/10.1097/CMR.0b013e32834640c0

[62] Welters, M.J., Bijker, M.S., Eeden, S.J., Franken, K.L., Melief, C.J., Offringa, R. and Burg, S.H. (2007) Multiple CD4 and CD8 T-Cell Activation Parameters Predict Vaccine Efficacy in Vivo Mediated by Individual DC-Activating Agonists. Vaccine, 25, 1379-1389. http://dx.doi.org/10.1016/j.vaccine.2006.10.049

[63] Speiser, D.E., Liénard, D., Rufer, N., Rubio-Godoy, V., Rimoldi, D., Lejeune, F., Krieg, A.M., Cerottini, J.C. and Romero, P. (2005) Rapid and Strong Human $\mathrm{CD}^{+}$T Cell Responses to Vaccination with Peptide, IFA, and CpG Oligodeoxynucleotide 7909. Journal of Clinical Investigation, 115, 739-746. http://dx.doi.org/10.1172/JCI23373

[64] Napolitani, G., Rinaldi, A., Bertoni, F., Sallusto, F. and Lanzavecchia, A. (2005) Selected Toll-Like Receptor Agonist Combinations Synergistically Trigger a T Helper Type 1-Polarizing Program in Dendritic Cells. Nature Immunology, 6, 769-776. http://dx.doi.org/10.1038/ni1223

[65] Boer, A.T., Diehl, L., van, Mierlo, G.J., Voort, E.I., Fransen, M.F., Krimpenfort, P., Melief, C.J., Offringa, R. and Toes, R.E. (2001) Longevity of Antigen Presentation and Activation Status of APC Are Decisive Factors in the Balance between CTL Immunity versus Tolerance. Journal of Immunology, 167, 2522-2528. http://dx.doi.org/10.4049/jimmunol.167.5.2522

[66] Khan, S., Bijker, M.S., Weterings, J.J., Tanke, H.J., Adema, G.J., Drijfhout, J.W., Melief, C.J., Overkleeft, H.S., Marel, G.A., Filippov, D.V., Burg, S.H. and Ossendorp, F. (2007) Distinct Uptake Mechanisms but Similar Intracellular Processing of Two Different Toll-Like Receptor Ligand-Peptide Conjugates in Dendritic Cells. Journal of Biological Chemistry, 282, 21145-21159. http://dx.doi.org/10.1074/jbc.M701705200

[67] Jackson, D.C., Lau, Y.F., Le, T., Suhrbier, A., Deliyannis, G., Cheers, C., Smith, C., Zeng, W. and Brown, L.E. (2004) A Totally Synthetic Vaccine of Generic Structure that Targets Toll-Like Receptor 2 on Dendritic Cells and Promotes Antibody or Cytotoxic T Cell Responses. Proceedings of the National Academy of Sciences of the United States of America, 101, 15440-15445. http://dx.doi.org/10.1073/pnas.0406740101

[68] Zwaveling, S., Ferreira, M.S., Nouta, J., Johnson, M., Lipford, G.B., Offringa, R., Burg, S.H. and Melief, C.J. (2002) Established Human Papillomavirus Type 16-Expressing Tumors Are Effectively Eradicated Following Vaccination with Long Peptides. Journal of Immunology, 169, 350-358. http://dx.doi.org/10.4049/jimmunol.169.1.350

[69] Peoples, G.E., Holmes, J.P., Hueman, M.T., Mittendorf, E.A., Amin, A., Khoo, S., Dehqanzada, Z.A., Gurney, J.M., Woll, M.M., Ryan, G.B., Storrer, C.E., Craig, D., Ioannides, C.G. and Ponniah, S. (2008) Combined Clinical Trial Results of a HER2/Neu (E75) Vaccine for the Prevention of Recurrence in High-Risk Breast Cancer Patients: U.S. Military Cancer Institute Clinical Trials Group Study I-01 and I-02. Clinical Cancer Research, 14, 797-803. http://dx.doi.org/10.1158/1078-0432.CCR-07-1448

[70] Benavides, L.C., Sears, A.K., Gates, J.D., Clifton, G.T., Clive, K.S., Carmichael, M.G., Holmes, J.P., Mittendorf, E.A., Ponniah, S. and Peoples, G.E. (2011) Comparison of Different HER2/Neu Vaccines in Adjuvant Breast Cancer Trials: Implications for Dosing of Peptide Vaccines. Expert Review of Vaccines, 10, 201-210. http://dx.doi.org/10.1586/erv.10.167

[71] Mittendorf, E.A., Clifton, G.T., Holmes, J.P., Clive, K.S., Patil, R., Benavides, L.C., Gates, J.D., Sears, A.K., Stojadinovic, A., Ponniah, S. and Peoples, G.E. (2012) Clinical Trial Results of the HER-2/Neu (E75) Vaccine to Prevent Breast Cancer Recurrence in High-Risk Patients: From US Military Cancer Institute Clinical Trials Group Study I-01 and I-02. Cancer, 118, 2594-2602. http://dx.doi.org/10.1002/cncr.26574

[72] Peoples, G.E., Goedegeburre, P.S., Smith, R., Linehan, D.C., Yoshino, I. and Eberlein, T.J. (1995) Breast and Ovarian Cancer-Specific Cytotoxic T Lymphocytes Recognize the Same HER2/Neu-Derived Peptide. Proceedings of the Na- 
tional Academy of Sciences of the United States of America, 92, 432-436. http://dx.doi.org/10.1073/pnas.92.2.432

[73] Schneble, E.J., Berry, J.S., Trappey, F.A., Clifton, G.T., Ponniah, S., Mittendorf, E. and Peoples, G.E. (2014) The HER2 Peptide Nelipepimut-S (E75) Vaccine (NeuVax ${ }^{\mathrm{TM}}$ ) in Breast Cancer Patients at Risk for Recurrence: Correlation of Immunologic Data with Clinical Response. Immunotherapy, 6, 519-531. http://dx.doi.org/10.2217/imt.14.22

[74] Mittendorf, E.A., Clifton, G.T., Holmes, J.P., Schneble, E., Echo, D., Ponniah, S. and Peoples, G.E. (2014) Final Report of the Phase I/II Clinical Trial of the E75 (nelipepimut-S) Vaccine with Booster Inoculations to Prevent Disease Recurrence in High-Risk Breast Cancer Patients. Annals of Oncology, 25, 1735-1742. http://dx.doi.org/10.1093/annonc/mdu211

[75] Zaks, T.Z. and Rosenberg, S.A. (1998) Immunization with a Peptide Epitope (p369-377) from HER-2/Neu Leads to Peptide-Specific Cytotoxic T Lymphocytes that Fail to Recognize HER-2/Neu+ Tumors. Cancer Research, 58, 49024908.

[76] Peoples, G.E., Gurney, J.M., Hueman, M.T., Woll, M.M., Ryan, G.B., Storrer, C.E., Fisher, C., Shriver, C.D., Ioannides, C.G. and Ponniah, S. (2005) Clinical Trial Results of a HER2/Neu (E75) Vaccine to Prevent Recurrence in High-Risk Breast Cancer Patients. Journal of Clinical Oncology, 23, 7536-7545. http://dx.doi.org/10.1200/JCO.2005.03.047

[77] Knutson, K.L., Schiffman, K. and Disis, M.L. (2001) Immunization with a HER-2/Neu Helper Peptide Vaccine Generates HER-2/Neu CD8 T-Cell Immunity in Cancer Patients. Journal of Clinical Investigation, 107, 477-484. http://dx.doi.org/10.1172/JCI11752

[78] Disis, M.L., Gooley, T.A., Rinn, K., Davis, D., Piepkorn, M., Cheever, M.A., Knutson, K.L. and Schiffman, K. (2002) Generation of T-Cell Immunity to the HER-2/Neu Protein after Active Immunization with HER-2/Neu Peptide-Based Vaccines. Journal of Clinical Oncology, 20, 2624-2632. http://dx.doi.org/10.1200/JCO.2002.06.171

[79] Salazar, L.G., Goodell, V., O’Meara, M., Knutson, K., Dang, Y., Rosa, C., Guthrie, K. and Disis, M.L. (2009) Persistent Immunity and Survival after Immunization with a HER2/Neu (HER2) Vaccine. ASCO Meeting Abstracts, 27, 3010.

[80] Amin, A., Benavides, L.C., Holmes, J.P., Gates, J.D., Carmichael, M.G., Hueman, M.T., Mittendorf, E.A., Storrer, C.E., Jama, Y.H., Craig, D., Stojadinovic, A., Ponniah, S. and Peoples, G.E. (2008) Assessment of Immunologic Response and Recurrence Patterns among Patients with Clinical Recurrence after Vaccination with a Preventive HER2/Neu Peptide Vaccine: From US Military Cancer Institute Clinical Trials Group Study I-01 and I-02. Cancer Immunology, Immunotherapy, 57, 1817-1825. http://dx.doi.org/10.1007/s00262-008-0509-2

[81] Clive, K.S., Tyler, J.A., Clifton, G.T., Holmes, J.P., Ponniah, S., Peoples, G.E. and Mittendorf, E.A. (2012) The GP2 Peptide: A HER2/Neu-Based Breast Cancer Vaccine. Journal of Surgical Oncology, 105, 452-458. http://dx.doi.org/10.1002/jso.21723

[82] Mittendorf, E.A., Holmes, J.P., Ponniah, S. and Peoples, G.E. (2008) The E75 HER2/Neu Peptide Vaccine. Cancer Immunology, Immunotherapy, 57, 1511-1521. http://dx.doi.org/10.1007/s00262-008-0540-3

[83] Dang, Y., Knutson, K.L., Goodell, V., Rosa, C., Salazar, L.G., Higgins, D., Childs, J. and Disis, M.L. (2007) Tumor Antigen-Specific T-Cell Expansion Is Greatly Facilitated by in Vivo Priming. Clinical Cancer Research, 13, 18831891. http://dx.doi.org/10.1158/1078-0432.CCR-06-2083

[84] Clifton, G.T., Holmes, J.P., Perez, S.A., Lorentz, D., Georgakopoulou, K., Benavides, L., Gates, J., Mittendorf, M., Ardavanis, A., Gritzapis, A., Ponniah, S., Papamichail, M. and Peoples, G. (2009) Interim Analysis of a Randomized Phase II Study of the Novel HER2/Neu Peptide (GP2) Vaccine to Prevent Breast Cancer Recurrence: United States Military Cancer Institute Clinical Trials Group Study I-05. Cancer Research, 69 (24 Suppl), Abstract No. 5110. http://dx.doi.org/10.1158/0008-5472.SABCS-09-5110

[85] Hung, K., Hayashi, R., Lafond-Walker, A., Lowenstein, C., Pardoll, D. and Levitsky, H. (1998) The Central Role of $\mathrm{CD}^{+} \mathrm{T}$ Cells in the Antitumor Immune Response. Journal of Experimental Medicine, 188, 2357-2368. http://dx.doi.org/10.1084/jem.188.12.2357

[86] Hu, H.M., Winter, H., Urba, W.J. and Fox, B.A. (2000) Divergent Roles for CD4 ${ }^{+}$T Cells in the Priming and Effector/ Memory Phases of Adoptive Immunotherapy. Journal of Immunology, 165, 4246-4253. http://dx.doi.org/10.4049/jimmunol.165.8.4246

[87] Protti, M.P., Monte, L.D. and Lullo, G.D. (2014) Tumor Antigen-Specific CD4 ${ }^{+}$T Cells in Cancer Immunity: From Antigen Identification to Tumor Prognosis and Development of Therapeutic Strategies. Tissue Antigens, 83, $237-246$. http://dx.doi.org/10.1111/tan.12329

[88] Sears, A.K., Perez, S.A., Clifton, G.T., Benavides, L.C., Gates, J.D., Clive, K.S., Holmes, J.P., Shumway, N.M., Van Echo, D.C., Carmichael, M.G., Ponniah, S., Baxevanis, C.N., Mittendorf, E.A., Papamichail, M. and Peoples, G.E. (2011) AE37: A Novel T-Cell-Eliciting Vaccine for Breast Cancer. Expert Opinion on Biological Therapy, 11, 15431550. http://dx.doi.org/10.1517/14712598.2011.616889

[89] Wiedermann, U., Davis, A.B. and Zielinski, C.C. (2013) Vaccination for the Prevention and Treatment of Breast Can- 
cer with Special Focus on Her-2/Neu Peptide Vaccines. Breast Cancer Research and Treatment, 138, 1-12. http://dx.doi.org/10.1007/s10549-013-2410-8

[90] Mittendorf, E.A., Holmes, J.P., Murray, J.L., Hofe, E. and Peoples, G.E. (2009) CD4 ${ }^{+}$T Cells in Antitumor Immunity: Utility of an Li-Key HER2/Neu Hybrid Peptide Vaccine (AE37). Expert Opinion on Biological Therapy, 9, 71-78. http://dx.doi.org/10.1517/14712590802614538

[91] Gates, J.D., Clifton, G.T., Benavides, L.C., Sears, A.K., Carmichael, M.G., Hueman, M.T., Holmes, J.P., Jama, Y.H., Mursal, M., Zacharia, A., Ciano, K., Khoo, S., Stojadinovic, A., Ponniah, S. and Peoples, G.E. (2010) Circulating Regulatory T Cells $\left(\mathrm{CD}^{+} \mathrm{CD}^{+} 5^{+} \mathrm{FOXP}^{+}\right)$Decrease in Breast Cancer Patients after Vaccination with a Modified MHC Class II HER2/Neu (AE37) Peptide. Vaccine, 28, 7476-7482. http://dx.doi.org/10.1016/j.vaccine.2010.09.029

[92] Xu, M. and Kallinteris, N.L. (2012) CD4 ${ }^{+}$T-Cell Activation for Immunotherapy of Malignancies Using Ii-Key/MHC Class II Epitope Hybrid Vaccines. Vaccine, 30, 2805-2810. http://dx.doi.org/10.1016/j.vaccine.2012.02.031

[93] Holmes, J.P., Benavides, L.C., Gates, J.D., Carmichael, M.G., Hueman, M.T., Mittendorf, E.A., Murray, J.L., Amin, A., Craig, D., Hofe, E., Ponniah, S. and Peoples, G.E. (2008) Results of the First Phase I Clinical Trial of the Novel II-Key Hybrid Preventive HER-2/Neu Peptide (AE37) Vaccine. Journal of Clinical Oncology, 26, 3426-3433. http://dx.doi.org/10.1200/JCO.2007.15.7842

[94] Baxevanis, C.N., Papamichail, M. and Perez, S.A. (2014) Therapeutic Cancer Vaccines: A Long and Winding Road to Success. Expert Review of Vaccines, 13, 131-144. http://dx.doi.org/10.1586/14760584.2014.852961

[95] Zhang, X., Gordon, J.R. and Xiang, J. (2002) Advances in Dendritic Cell-Based Vaccine of Cancer. Cancer Biotherapy and Radiopharmaceuticals, 17, 601-619. http://dx.doi.org/10.1089/108497802320970217

[96] Merad, M., Sathe, P., Helft, J., Miller, J. and Mortha, A. (2013) The Dendritic Cell Lineage: Ontogeny and Function of Dendritic Cells and Their Subsets in the Steady State and the Inflamed Setting. Annual Review of Immunology, 31, 563-604. http://dx.doi.org/10.1146/annurev-immunol-020711-074950

[97] Fong, L. and Engleman, E.G. (2000) Dendritic Cells in Cancer Immunotherapy. Annual Review of Immunology, 18, 245-273. http://dx.doi.org/10.1146/annurev.immunol.18.1.245

[98] Palucka, K. and Banchereau, J. (2012) Cancer Immunotherapy via Dendritic Cells. Nature Reviews Cancer, 12, 265277. http://dx.doi.org/10.1038/nrc3258

[99] Blattman, J.N. and Greenberg, P.D. (2004) Cancer Immunotherapy: A Treatment for the Masses. Science, 305, 200205. http://dx.doi.org/10.1126/science.1100369

[100] Galluzzi, L., Senovilla, L., Vacchelli, E., Eggermont, A., Fridman, W.H., Galon, J., Sautès-Fridman, C., Tartour, E., Zitvogel, L. and Kroemer, G. (2012) Trial Watch: Dendritic Cell-Based Interventions for Cancer Therapy. OncoImmunology, 1, 1111-1134. http://dx.doi.org/10.4161/onci.21494

[101] Tyagi, R.K., Mangal, S., Garg, N. and Sharma, P.K. (2009) RNA-Based Immunotherapy of Cancer: Role and Therapeutic Implications of Dendritic Cells. Expert Review of Anticancer Therapy, 9, 97-114. http://dx.doi.org/10.1586/14737140.9.1.97

[102] Zappasodi, R., Pupa, S.M., Ghedini, G.C., Bongarzone, I., Magni, M., Cabras, A.D., Colombo, M.P., Carlo-Stella, C., Gianni, A.M. and Nicola, M. (2010) Improved Clinical Outcome in Indolent B-Cell Lymphoma Patients Vaccinated with Autologous Tumor Cells Experiencing Immunogenic Death. Cancer Research, 70, 9062-9072. http://dx.doi.org/10.1158/0008-5472.CAN-10-1825

[103] Vacchelli, E., Vitale, I., Eggermont, A., Fridman, W.H., Fučíková, J., Cremer, I., Galon, J., Tartour, E., Zitvogel, L., Kroemer, G. and Galluzzi, L. (2013) Trial Watch: Dendritic Cell-Based Interventions for Cancer Therapy. OncoImmunology, 2, e25771. http://dx.doi.org/10.4161/onci.25771

[104] Sun, J.C. and Bevan, M.J. (2003) Defective CD8 T Cell Memory Following Acute Infection without CD4 T Cell Help. Science, 300, 339-342. http://dx.doi.org/10.1126/science.1083317

[105] Dunkle, A., Dzhagalov, I., Gordy, C. and He, Y.W. (2013) Transfer of CD8 ${ }^{+}$T Cell Memory Using Bcl-2 as a Marker. Journal of Immunology, 190, 940-947. http://dx.doi.org/10.4049/jimmunol.1103481

[106] Harlin, H., Meng, Y., Peterson, A.C., Zha, Y., Tretiakova, M., Slingluff, C., McKee, M. and Gajewski, T.F. (2009) Chemokine Expression in Melanoma Metastases Associated with CD8 ${ }^{+}$T-Cell Recruitment. Cancer Research, 69, 3077-3085. http://dx.doi.org/10.1158/0008-5472.CAN-08-2281

[107] Sakai, Y., Morrison, B.J., Burke, J.D., Park, J.M., Terabe, M., Janik, J.E., Forni, G., Berzofsky, J.A. and Morris, J.C. (2004) Vaccination by Genetically Modified Dendritic Cells Expressing a Truncated Neu Oncogene Prevents Development of Breast Cancer in Transgenic Mice. Cancer Research, 64, 8022-8028. http://dx.doi.org/10.1158/0008-5472.CAN-03-3442

[108] Viehl, C.T., Becker-Hapak, M., Lewis, J.S., Tanaka, Y., Liyanage, U.K., Linehan, D.C., Eberlein, T.J. and Goedegebuure, P.S. (2005) A Tat Fusion Protein-Based Tumor Vaccine for Breast Cancer. Annals of Surgical Oncology, 12, 517-525. http://dx.doi.org/10.1245/ASO.2005.06.028 
[109] Chen, Y., Emtage, P., Zhu, Q., Foley, R., Muller, W., Hitt, M., Gauldie, J. and Wan, Y. (2001) Induction of ErbB-2/Neu-Specific Protective and Therapeutic Antitumor Immunity Using Genetically Modified Dendritic Cells: Enhanced Efficacy by Cotransduction of Gene Encoding IL-12. Gene Therapy, 8, 316-323. http://dx.doi.org/10.1038/sj.gt.3301396

[110] Tatsumi, T., Takehara, T., Yamaguchi, S., Sasakawa, A., Miyagi, T., Jinushi, M., Sakamori, R., Kohga, K., Uemura, A., Ohkawa, K., Storkus, W.J. and Hayashi, N. (2007) Injection of IL-12 Gene-Transduced Dendritic Cells into Mouse Liver Tumor Lesions Activates both Innate and Acquired Immunity. Gene Therapy, 14, 863-871. http://dx.doi.org/10.1038/sj.gt.3302941

[111] Chen, Z., Huang, H., Chang, T., Carlsen, S., Saxena, A., Marr, R., Xing, Z. and Xiang, J. (2002) Enhanced HER-2/Neu-Specific Antitumor Immunity by Cotransduction of Mouse Dendritic Cells with Two Genes Encoding HER-2/Neu and Alpha Tumor Necrosis Factor. Cancer Gene Therapy, 9, 778-786. http://dx.doi.org/10.1038/sj.cgt.7700498

[112] Chan, T., Sami, A., El-Gayed, A., Guo, X. and Xiang, J. (2006) HER-2/Neu-Gene Engineered Dendritic Cell Vaccine Stimulates Stronger HER-2/Neu-Specific Immune Responses Compared to DNA Vaccination. Gene Therapy, 13, 1391-1402. http://dx.doi.org/10.1038/sj.gt.3302797

[113] Sas, S., Chan, T., Sami, A., El-Gayed, A. and Xiang, J. (2008) Vaccination of Fiber-Modified Adenovirus-Transfected Dendritic Cells to Express HER-2/Neu Stimulates Efficient HER-2/Neu-Specific Humoral and CTL Responses and Reduces Breast Carcinogenesis in Transgenic Mice. Cancer Gene Therapy, 15, 655-666. http://dx.doi.org/10.1038/cgt.2008.18

[114] Brossart, P., Wirths, S., Stuhler, G., Reichardt, V.L., Kanz, L. and Brugger, W. (2000) Induction of Cytotoxic T-Lymphocyte Responses in Vivo after Vaccinations with Peptide-Pulsed Dendritic Cells. Blood, 96, 3102-3108.

[115] Morse, M.A., Hobeika, A., Osada, T., Niedzwiecki, D., Marcom, P.K., Blackwell, K.L., Anders, C., Devi, G.R., Lyerly, H.K. and Clay, T.M. (2007) Long-Term Disease-Free Survival and T Cell and Antibody Responses in Women with High-Risk HER2 ${ }^{+}$Breast Cancer Following Vaccination against Her2. Journal of Translational Medicine, 5, 42. http://dx.doi.org/10.1186/1479-5876-5-42

[116] Peethambaram, P.P., Melisko, M.E., Rinn, K.J., Alberts, S.R., Provost, N.M., Jones, L.A., Sims, R.B., Lin, L.R., Frohlich, M.W. and Park, J.W. (2009) A Phase I Trial of Immunotherapy with Lapuleucel-T (APC8024) in Patients with Refractory Metastatic Tumors that Express HER-2/Neu. Clinical Cancer Research, 15, 5937-5944. http://dx.doi.org/10.1158/1078-0432.CCR-08-3282

[117] Disis, M., Dang, Y., Bates, N., Higgins, D., Childs, J., Slota, M., Coveler, A., Jackson, E., Waisman, J. and Salaza, L. (2010) Phase II Study of a HER-2/Neu (HER2) Intracellular Domain (ICD) Vaccine Given Concurrently with Trastuzumab in Patients with Newly Diagnosed Advanced Stage Breast Cancer. Cancer Research, 69, 5102. http://dx.doi.org/10.1158/0008-5472.SABCS-09-5102

[118] Czerniecki, B.J., Koski, G.K., Koldovsky, U., Xu, S., Cohen, P.A., Mick, R., Nisenbaum, H., Pasha, T., Xu, M., Fox, K.R., Weinstein, S., Orel, S.G., Vonderheide, R., Coukos, G., DeMichele, A., Araujo, L., Spitz, F.R., Rosen, M., Levine, B.L., June, C. and Zhang, P.J. (2007) Targeting HER-2/Neu in Early Breast Cancer Development Using Dendritic Cells with Staged Interleukin-12 Burst Secretion. Cancer Research, 67, 1842-1852. http://dx.doi.org/10.1158/0008-5472.CAN-06-4038

[119] Disis, M.L., Wallace, D.R., Gooley, T.A., Dang, Y., Slota, M., Lu, H., Coveler, A.L., Childs, J.S., Higgins, D.M., Fintak, P.A., dela Rosa, C., Tietje, K., Link, J., Waisman, J. and Salazar, L.G. (2009) Concurrent Trastuzumab and HER2/Neu-Specific Vaccination in Patients with Metastatic Breast Cancer. Journal of Clinical Oncology, 27, 46854692. http://dx.doi.org/10.1200/JCO.2008.20.6789

[120] Benavides, L.C., Gates, J.D., Carmichael, M.G., Patil, R., Holmes, J.P., Hueman, M.T., Mittendorf, E.A., Craig, D., Stojadinovic, A., Ponniah, S. and Peoples, G.E. (2009) The Impact of HER2/Neu Expression Level on Response to the E75 Vaccine: From U.S. Military Cancer Institute Clinical Trials Group Study I-01 and I-02. Clinical Cancer Research, 15, 2895-2904. http://dx.doi.org/10.1158/1078-0432.CCR-08-1126

[121] Hamilton, E., Blackwell, K., Hobeika, A.C., Clay, T.M., Broadwater, G., Ren, X.R., Chen, W., Castro, H., Lehmann, F., Spector, N., Wei, J., Osada, T. and Lyerly, H.K. (2012) Phase I Clinical Trial of HER2-Specific Immunotherapy with Concomitant HER2 Kinase Inhibition. Journal of Translational Medicine, 10, 28. http://dx.doi.org/10.1186/1479-5876-10-28 